

\section{ASSESSING THE FINANCIAL SUSTAINABILITY OF JAMAIGA'S HIV PROGRAM}


(C) 2013 International Bank for Reconstruction and Development / International Development Association or The World Bank

1818 H Street NW

Washington DC 20433

Telephone: 202-473-1000

Internet: www.worldbank.org

This work is a product of the staff of The World Bank with external contributions. The findings, interpretations, and conclusions expressed in this work do not necessarily reflect the views of The World Bank, its Board of Executive Directors or the governments they represent.

The World Bank does not guarantee the accuracy of the data included in this work. The boundaries, colors, denominations, and other information shown on any map in this work do not imply any judgment on the part of The World Bank concerning the legal status of any territory or the endorsement or acceptance of such boundaries.

\section{Rights and Permissions}

The material in this work is subject to copyright. Because The World Bank encourages dissemination of its knowledge, this work may be reproduced, in whole or in part, for noncommercial purposes as long as full attribution to this work is given.

Any queries on rights and licenses, including subsidiary rights, should be addressed to the Office of the Publisher, The World Bank, $1818 \mathrm{H}$ Street NW, Washington, DC 20433, USA; fax: 202-522-2422; e-mail: pubrights@worldbank.org. 


\section{Table of Contents}

Acknowledgments $\quad \mathrm{V}$

Acronyms and Abbreviations vii

Executive Summary 1

HIV/AIDS in Jamaica: the State of the Epidemic and of the National Response 2

Projecting the Cost of the National Response to HIV/AIDS 3

HIV Incidence and the Cost of the National Response 3

Sustainability of the National Response to HIV/AIDS 5

$\begin{array}{ll}\text { I. Introduction } & 7\end{array}$

II. The State of HIVIAIDS and of the HIVIAIDS Response 9

The State of the Epidemic 9

Costs and the Financing of the National Response to HIV/AIDS 11

III. Projecting the Costs of the National Response to HIVIAIDS 17

$\begin{array}{ll}\text { Epidemiological Projections } & 17\end{array}$

Assumptions on Unit Costs and Coverage Rates 20

$\begin{array}{ll}\text { Projected Costs of HIV/AIDS Program } & 20\end{array}$

Some Policy Lessons 23

IV. HIV Incidence and the Costs of the HIVIAIDS Response 25

The Costs Incurred by each Additional HIV Infection 25

Assessing the Cost-Effectiveness of HIV Prevention Interventions 26

Prevention Policies and the Drivers of HIV Incidence 28

V. Fiscal Evaluation of the Costs of the HIVIAIDS Program 29

VI. Sustainability of the National Response to HIVIAIDS 33

Implications of Reduced Availability of External Financing 33

Funding Treatment Costs 36

$\begin{array}{ll}\text { VII. Conclusions } & 37\end{array}$ 
References $\quad 39$

$\begin{array}{ll}\text { Appendix on Methodology } & 41\end{array}$

\section{Figures}

ES1. Mortality by Cause $\quad 2$

ES2. Composition of Spending Under NationalResponse to HIVIAIDS, 2010/11 2

ES3. Costs of National Response to HIV/AIDS2010-2030 3

ES4. Jamaica: Costs of One Additional Infection 4

ES5. Jamaica: Fiscal Costs of HIV/AIDS, "Commitment Basis", 2010-2030 4

ES6. Fiscal Costs of HIVIAIDS, Current and Commitments, Across Scenarios 5

1. The Course of the HIV Epidemic in Jamaica, 1980-2010 10

2. Mortality by Cause, 2008

3. Mortality by Age and Sex, 2005-10 12

4. Composition of Spending Under National Response to HIV/AIDS, 2010/11 15

5. People Living with HIV/AIDS, 2010-2030 18

6. State of Epidemic Across 3 Scenarios, 2010-2030 19

7. Cost of National Response to HIV/AIDS, 3 Scenarios, 2010-2030 21

8. Costs of National Response to HIV/AIDS, 2010-2030, Across Scenarios 22

9. Costs of One Additional Infection, 2012

10. Fiscal Costs of HIV/AIDS, Commitment Basis, 2010-2030 30

11. Fiscal Costs of HIV/AIDS, Current and Commitments, Across Scenarios 31

12. Composition of Financing of National Response to HIV/AIDS, 201034

13. Role of External HIV/AIDS Financing, 2009

14. Domestic Financing Need and Rate of External Support 35

\section{Tables}

1. Summary Health Indicators and Impact of HIVIAIDS 11

2. Costs and Financing of National Response to HIV/AIDS, 2009/10-2010/11 13

3. Costs Incurred by HIV Infections, by Population Group 28

A1. Costs of Jamaica's National Response to HIVIAIDS 43

\section{Boxes}

1. Macroeconomic and Fiscal Context of National Response to HIV/AIDS 13

2. Health Spending and Access to Health Services 14

3. Macroeconomic Impact of HIV/AIDS $\quad 22$

4. Estimating the Financial Costs of New Infections 27 


\section{Acknowledgments}

This study was undertaken at the request of the Government of Jamaica to inform its future policies. Led and financed by the World Bank, it was conducted in collaboration with the Government of Jamaica and the Joint United Nations Programme on HIVIAIDS (UNAIDS). The task team was led by Elizabeth Mziray and included Markus Haacker, Shiyan Chao, and Mario Mendez. Markus Haacker was the lead author for the report, and Mario Mendez provided administrative support.

The study was overseen by a local study steering committee chaired by the Planning Institute of Jamaica and included representatives from the Ministry of Health, Ministry of Finance, UNAIDS and the World Bank. The team would like to thank the Honorable Dr. Fenton Douglas, Minister of Health, Dr. Jean Dixon, Dr. Kevin Harvey, Dr. Nicola Skyers, and Ms. Barbara Scott from the Government of Jamaica, and Dr. Ernest Massiah and Dr. Pierre Somse from UNAIDS, for their guidance and support.

The study has benefitted from input and suggestion from numerous government officials, including Dr. Sharlene Jarrett, Suzanne Watson, Terry Ann Frith, Sannia Sutherland, Edgar Watson, and Andrew Brown from the National HIV/STI Programme; Michael Maragh, Sandra Graham, and Evelyn Bloomfield from Ministry of Health; Walter James, Andrea Sheppard, Saskia Frater-Smith, Easton Williams, and Hugh Morris from Planning Institute of Jamaica; Othneil Hemans, Barbara Hew, and Carlene Momsas from Ministry of Finance, and Dunstan E. Bryan from Ministry of Labor and Social Security.

Additionally, the study has also benefitted from contributions by the World Bank Prevention Science and Mathematical Modeling Reference Group, Dr. Timothy Hallett (Imperial College), Dr. Laith Abu-Raddad (Cornell University), Erva-Jean Stevens (UNAIDS), Cary Reid and Katherine Guerra (Clinton Health Access Initiative), Andrew Fearon, Dr. Geoffrey Barrow; as well as a discussion with Dr. Peter Figueroa; and comments received at the presentation of the draft report to government officials and development partners in April 2012. The team would like to thank the peer reviewers from the World Bank, Christine Pena, Aparnaa Somanathan, and Ajay Tandon; and acknowledge the support and guidance received from Nicole Klingen, David Wilson, Keith Hansen, Joana Godinho, Leslie Elder, and Jody Kusek. Finally, the team thanks Gregory Wlosinski, Printing and Multimedia, General Services for graphic design of the report. 


\section{Acronyms and Abbreviations}

$\begin{array}{ll}\text { AIDS } & \text { Acquired immunodeficiency syndrome } \\ \text { CDA } & \text { Child Development Agency } \\ \text { FY } & \text { Financial year } \\ \text { GDP } & \text { Gross domestic product } \\ \text { Global Fund } & \text { Global Fund to Fight AIDS, Tuberculosis and Malaria } \\ \text { HIV } & \text { Human immunodeficiency virus } \\ \text { MoH } & \text { Ministry of Health } \\ \text { MOT } & \text { Modes of transmission } \\ \text { NASA } & \text { National AIDS Spending Assessment } \\ \text { NGO } & \text { Non-governmental organization } \\ \text { NHF } & \text { National Health Fund } \\ \text { NHP } & \text { National HIV/STI Programme } \\ \text { NSP } & \text { National strategic plan } \\ \text { PIOJ } & \text { Planning Institute of Jamaica } \\ \text { PMTCT } & \text { Prevention of mother-to-child transmission } \\ \text { STI } & \text { Sexually transmitted infection } \\ \text { UN } & \text { United Nations } \\ \text { UNAIDS } & \text { Joint United Nations Programme on HIVIAIDS } \\ \text { UNGASS } & \text { United Nations General Assembly Special Session (on HIVIAIDS) }\end{array}$




\section{Executive Summary}

Jamaica has made many notable achievements in the fight against HIVIAIDS, which include a robust treatment program and improved HIV prevention programs that increasingly focus on the key drivers of the HIV epidemic and which are based on evidence. These attainments have resulted in a sustained decline in the estimated incidence of HIV and in a reduction in AIDS mortality.

The national response to HIV/AIDS in Jamaica is currently financed by the Government as well as by several external sources, including the World Bank, the Global Fund to Fight AIDS, Tuberculosis and Malaria (Global Fund) and the United States government. It is expected, however, that external financing will cease or be significantly reduced in the next two years. As a result, a substantial increase in domestic financing for the national HIVIAIDS response will be needed. However, public debt levels are high, and the country is feeling the repercussions of the global financial crisis, thus the availability of domestic resources is and will be very tight. Any shortfall in financing whether domestic, external or both will have serious implications for the delivery of HIV services. The Government of Jamaica requested this study so as to inform its future HIVIAIDS policy response. This study is one input in a series of actions that the Government will undertake to formulate a future sustainability plan and investment framework for the National HIV Program.

This study was led and financed by the World Bank and conducted in collaboration with the Government of Jamaica and UNAIDS. The study aimed to assess the sustainability of Jamaica's National HIV Program from a fiscal perspective. Specifically, the purpose of the study was to:

1. review current spending on HIV/AIDS and the sources of financing;

2. estimate the fiscal burden of the national HIVIAIDS response and assess the outlook for external financing of the HIV program;

3. project how the epidemic will unfold as well as what the costs would be under different potential scenarios; and

4. provide recommendations to inform policy decisions. 
Figure ES1. Mortality by Cause

Figure ES1.A. Jamaica: Composition of Mortality, 2008 (Ages 15-59)

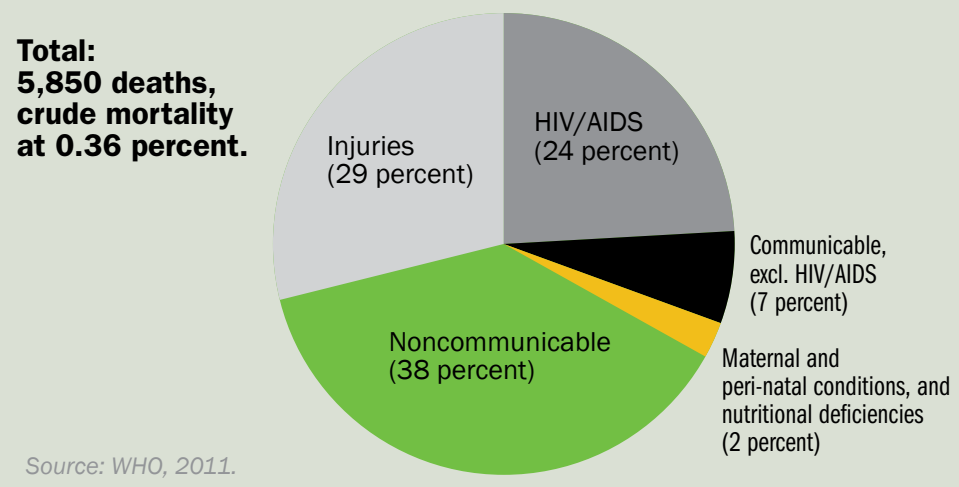

Figure ES1.B. Jamaica: Mortality by Age and Sex 2005-2010

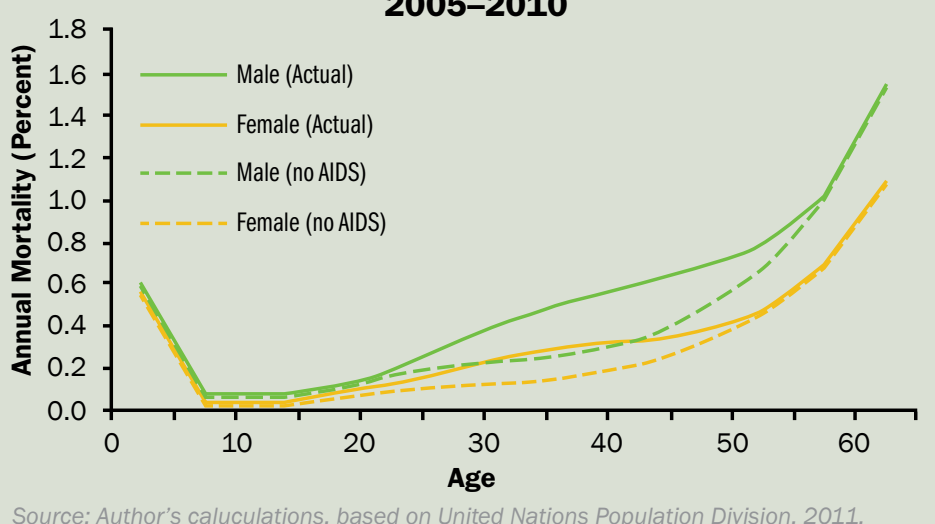

\section{HIV/AIDS in Jamaica: the State of the Epidemic and of the National Response}

It is estimated that 1.7 percent of the population aged between 15 and 49 years are HIV-positive. However, the prevalence rate is much higher among men who have sex with men (32 percent) and among commercial sex workers (five percent). UNAIDS $(2010 a, b)$ estimates that 32,000 people were living with HIV in 2009 (i.e., 1.1 percent of the total population of 2.8 million). HIV prevalence has declined from the peak of 2.2 percent (among those aged 15-49 years) it had reached in 1995.

HIVIAIDS has reversed the health gains that had been achieved in Jamaica over many years. Whereas life expectancy in the country grew at an average rate of 0.2 years annually between 1955/60 and 2005/10, life expectancy at birth was 1.6 years lower in 2005/10 as a result of HIVIAIDS. However, such aggregate estimates mask the impact of HIVIAIDS among specific population groups. For example, HIVIAIDS accounts for one-quarter of deaths between those aged 15 to 59 years and is the leading cause of death among males between the ages of 30 and 44 years (Figure ES1).
The national response to HIVIAIDS took off in 1988, when the National AIDS Committee was established and the first national HIV plan was launched. From 2009/10 to 2010/11, the cost of the national response increased from $J \$ 1,680$ million (US\$ 19.3 million) to J\$ 1,727 million (US\$20.4 million).

The largest component of HIVIAIDS spending is on prevention (J\$ 676 million in 2009/10, and $\mathbf{J} 625$ million in 2010/11, see Figure ES2). A large share of prevention spending was geared towards "communication for social and behavioral change" targeting the general or young population. In addition, the program also included measures targeting sex workers and their clients, men who have sex with men and drug users (about I\$ 10 million-equivalent to US\$120,000 - each in 2010/11, according to the National AIDS Spending Assessment, or NASA, see Ministry of Health and UNAIDS (2012)). Treatment and care absorbed J\$ 469 million (US\$ 5.5 million) in 2010/11, the bulk of which is accounted for by the cost of antiretroviral therapy (19 percent of total spending in 2010/11).

\section{Figure ES2. Composition of Spending Under National Response to HIV/AIDS, 2010/11 (Percent of total)}
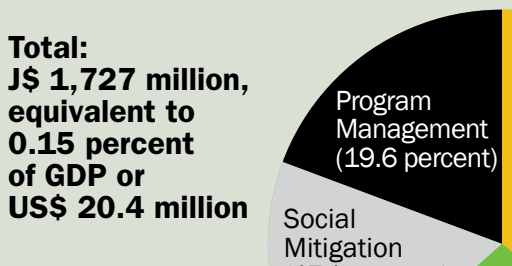

Prevention (36.2 percent) 
Figure ES3. Costs of National Response to HIV/AIDS 2010-2030 (declining HIV incidence)

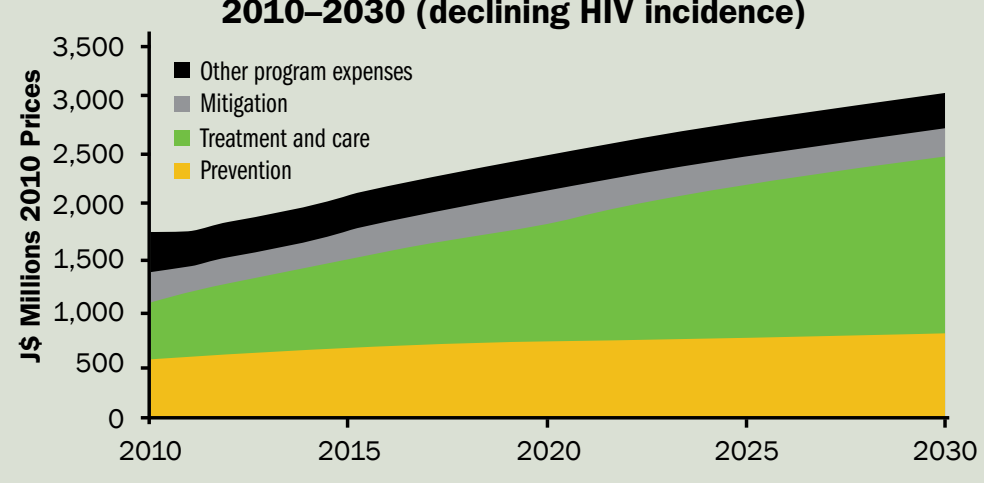

Source: Author's estimates and projections.

\section{Projecting the Cost of the National Response to HIV/AIDS}

Many factors influence the course of the HIV/AIDS epidemic. Therefore, this study makes some assumptions, based on a set of key factors, to project the future course of the epidemic in Jamaica. This analysis is reflected in three scenarios:

- $\quad$ Scenario 1 (declining HIV incidence): The number of new adult infections declines from 2,000 in 2010 to around 1,680 by 2018 (i.e., by 2.2 percent annually) and thereafter declines at a slower rate of one percent annually. In this scenario, HIV incidence declines from 0.14 percent (ages 15-49) in 2010 to 0.11 percent in 2030 .

- $\quad$ Scenario 2 (constant HIV incidence): The number of new infections remains constant at 2,000 from 2010. HIV incidence rates also remain broadly constant at about 0.14 percent.

- $\quad$ Scenario 3 (increasing HIV incidence): The number of new infections increases from 2,000 in 2010 to 2,300 by 2018 and thereafter grows more slowly by one percent annually to 2,600. HIV incidence increases from 0.14 percent (ages 15-49) in 2010 to 0.19 percent by 2030 .

In each of the scenarios, the number of people living with HIV/ AIDS increases over the period 2010 to 2030 (to 34,000 in Scenario 1; to 39,500 in Scenario 2; and to 45,200 in Scenario 3). This increaseeven in the scenarios with declining or constant HIV incidenceresults from a steep increase in the number of people receiving treatment and, therefore, living longer: from 7,900 in 2010 to between 24,900 (Scenario 1) and 30,600 (Scenario 3) in 2030. The number of people receiving treatment, however, barely differs across the scenarios for the first 10 years of projections. This is because in the case of HIV there is a long lag between the time of infection and the need for treatment.

Largely as a result of the increasing cost of treatment, the spending needs for the country rises steeply in all the scenarios-from $J \$ 1.7$ billion (US\$ 20.4 million) in 2010 to between I\$ 3.1 billion (US\$ 36 million) and J\$ 3.4 billion (US\$ 40.2 million) in 2030 (in constant 2010 prices). This is illustrated for Scenario 1 in Figure ES3. However, relative to GDP, this cost increase is less pronounced because GDP is also projected to increase over this period. The spending needs rise from 0.15 percent of GDP to between 0.20 and 0.22 percent of GDP.

Comparing the scenarios, the difference in cost is remarkably smallby 2030 , the total cost of the national response to HIVIAIDS is only 10 percent lower in Scenario 1 than in Scenario 3. The difference in cost (11 percent) is much smaller than the differences in the number of people receiving treatment (19 percent) or the number of new infections (43 percent). This small difference in costs reflects the long lag between the time of HIV infection and the time when people need treatment. While increasingly important over the projection period, treatment need may occur well over a decade after infection. In the case of second-line treatment (i.e., when the patient no longer responds to first-line treatment and the drug regimen needs to be switched to more expensive drugs) this lag is especially long.

\section{HIV Incidence and the Cost of the National Response}

The cost of the national response to HIVIAIDS is projected to rise steeply over the coming years, largely as a consequence of the increasing numbers of people living with HIVIAIDS requiring treatment. In the short-term, this rise in costs is not very responsive to changes in HIV incidence. This apparent disconnect is a result of the long lag between infection and treatment need and also because, as a persistent health condition, HIVIAIDS requires ongoing treatment. Figure ES4 summarizes the expected cost of providing services to one person living with HIVIAIDS. The cost rises to about J\$40,000 (US\$ 460 ) annually over the 15 years following an infection, mainly owing to the increasing probability that the person will require and receive (first-line) treatment. Subsequently, the expected cost declines owing to declining survival. This decline is moderated, however, by the increasing number of people who switch to more expensive second-line treatment, which means that the average unit cost of treatment increases for people surviving longer. Calculating the projected total 
Figure ES4. Jamaica: Costs of One Additional Infection

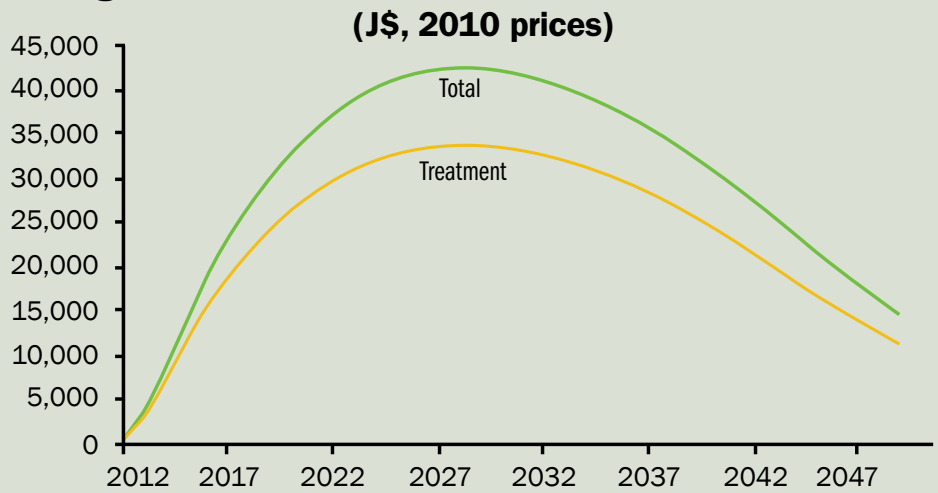

Source: Author's calculations.
Figure ES5. Jamaica: Fiscal Costs of HIV/AIDS, "Commitment Basis", 2010-2030 (Percent of GDP)

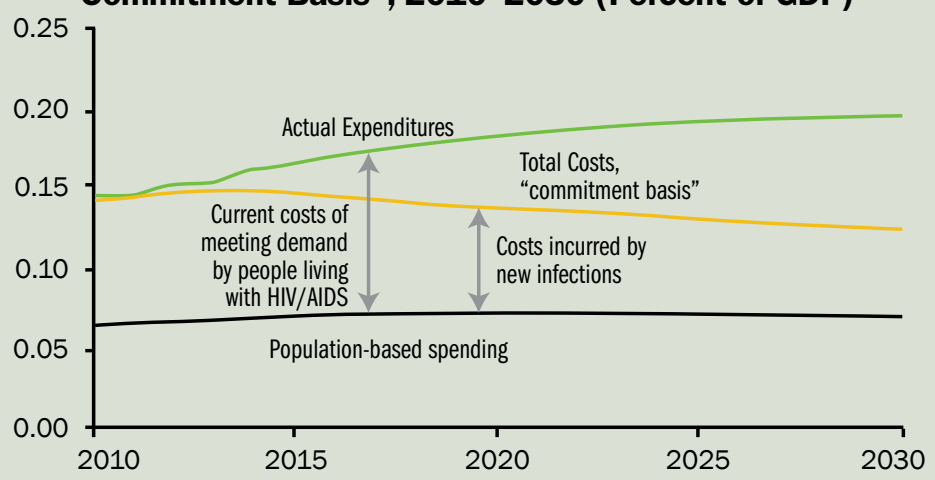

Source: Author's estimates and projections.

Figure is based on Scenario 1, in which HIV incidence declines. costs incurred over time by each infection is relevant for assessing how cost-effective HIV prevention interventions will be.

To assess the cost-effectiveness of a prevention intervention from a fiscal perspective, one needs to relate the outcome (HIV preventions averted, or the resulting health gains) to the cost of achieving it, as well as the financial savings from the reduced demand for HIV/ AIDS-related services such as treatment. To achieve this, it is necessary to evaluate the total cost caused by one infection over time (the lifetime of the infected individual). As most of the costs of treatment and other services in the case of HIVIAIDS will only become payable at a later stage in the person's infection, most of this initial outlay could be invested (or not borrowed) for an extended period. The expected future cost may, therefore, be discounted by an appropriate interest rate until it must be paid in reality. Applying an interest rate of five percent to discount the expected future cost, the estimated cost caused by one adult HIV infection is equal to $\$ \$ 500,000$ (equivalent to US\$5,800), which is about the level of GDP per capita in Jamaica. This means that preventing one HIV infection at a cost of less than this, reduces the financial cost of the national response to HIVIAIDS, and is a good financial investment, besides the positive health benefit. For an HIV infection averted at a higher cost, the financial saving of $\$ \$ 500,000$ needs to be subtracted from the overall cost to assess the cost-effectiveness of the intervention.

The estimates of the costs incurred by one infection also yield a clearer picture of the evolving fiscal burden of HIVIAIDS. HIVIAIDS spending in one year can be summarized as the sum of all "population-based" spending (largely prevention spending) that cannot be directly allocated to people living with HIVIAIDS and the cost incurred by all new infections (i.e. the number of new infections multiplied by the financial costs per HIV infection). To visualize this, Figure ES5 compares current HIVIAIDS spending and new costs or spending commitments caused by HIV infections in the case of Scenario 1 (declining incidence). Actual spending increases throughout the projection period. Initially, the financial commitments caused by new HIV infections are about equal to current spending on people living with HIVIAIDS, at 0.08 percent of GDP. Additionally, population-based spending absorbs 0.06 percent of GDP. Because of declining HIV incidence, the cost incurred by new infections comes down to 0.05 percent of GDP by 2030. While current spending increases, largely as a consequence of increasing treatment coverage and a build-up in the demand for treatment of past HIV infections, the new demands for fiscal resources for the national response to HIVIAIDS (to meet the demand for services caused by new HIV infections) declines over the projection period.

The differences in the fiscal costs involved between the three scenarios are illustrated in Figure ES6. By 2015, when actual spending barely begins to increase, the costs incurred by new infections are over J $\$ 100$ million (US\$ 1.3 million, about 0.01 percent of GDP) lower in the scenario with reduced HIV incidence (Scenario 1) when compared to Scenario 2 with constant HIV incidence, and by over I\$ 200 million (US\$2.4 million) compared to Scenario 3 with increasing HIV incidence (at constant 2010 prices). In Scenario 2 (constant HIV incidence), this difference (relative to Scenario 1) increases to J\$ 196 million (US\$ 2.3 million) by 2020 and to J\$294 million (US\$ 3.5 million) by 2030, while in Scenario 3 with increasing HIV incidence it increases to J $\$ 378$ million (US\$ 4.5 million) by 2020 and to J\$ 623 million (US\$ 7.3 million) by 2030.

These findings are relevant for the design and evaluation of HIVIAIDS policies because they provide:

1. Estimates of the financial implications of alternative HIVIAIDS policies, including the implications of changes in HIV incidence for spending needs.

2. A tool that helps to rank alternative policies in terms of their cost-effectiveness.

3. The consequences of higher or lower effectiveness of HIV prevention interventions. 


\section{Figure ES6. Fiscal Costs of HIV/AIDS, Current and \\ Commitments, Across Scenarios (Percent of GDP)}

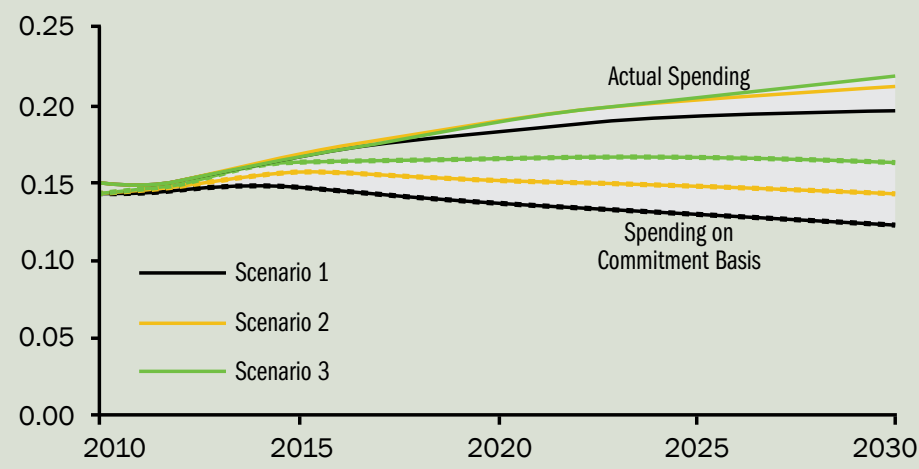

Source: Author's estimates.

The analysis supports the design of cost-effective HIV/AIDS policies by linking: (1) the costs of alternative HIV prevention interventions, (2) their outcomes for the course of the epidemic and (3) the consequences, assessed in terms of the costs of the resulting demand for HIVIAIDS services.

One of the most important consequences of new infections is the potential to cause further HIV infections (i.e., once infected an individual is able to infect others, who in turn are able to infect further individuals). This is an important issue in Jamaica, where the epidemic is concentrated. When the cost of such "downstream" infections is taken into account, the financial consequences of new infections are much larger than the cost incurred directly by one infection. The potential for downstream infections differs widely across the population according to sexual risk behavior. For individuals characterized by "low-risk" sexual behavior, "downstream" infections add about 60-80 percent to the cost incurred by one infection. For female sex workers, on the other hand, the expected cost of "downstream" infections is four times higher than the direct costs attributable to a single infection; for men who have sex with men, this cost is ten times higher.

\section{Sustainability of the National Response to HIV/AIDS}

Whether the national HIVIAIDS response is financially sustainable depends on how the country deals with the challenges that arise primarily from: (1) the increasing cost of providing HIVIAIDS services to the greatly expanding number of people eligible for and receiving treatment; and (2) the uncertain outlook of external funding.

In 2010/11, the Government of Jamaica met almost one third of total spending (31 percent). External financing, meanwhile, accounted for 69 percent of the cost of the national response to HIVIAIDS. By far the most substantial external financial contribution was from the Global Fund (49 percent of total spending), followed by the World Bank (9 percent of total spending) and the United States Government (2 percent of total spending).

The external financing from all the main donors is set to end over the next few years, and the funding outlook is uncertain beyond this period. In the face of rising spending needs, a decline in the rate of external support will result in an even steeper increase in domestic funding needs. For example, under Scenario 1 (declining HIV incidence), if the rate of external support was to decline from 69 to 45 percent, then domestic funding needs will need to double by 2015-from J\$ 539 million (US\$ 6.3 million) in 2010 to J\$1,144 million (US\$ 13.5 million) in 2015-and will need to increase to J\$ 1,353 million (US\$ 15.9 million) by 2020 and $\mathbf{~ \$ 1 , 6 8 3 ~ m i l l i o n ~}$ (US\$19.8 million) by 2030. The consequences of a decline in external funding are fairly even across the three scenarios due to the fact that changes in HIV incidence do not affect spending immediately (as there is a lag in the need for treatment after each incidence of infection). Nevertheless, in the long run successful prevention efforts will reduce government spending, which will play an important role in helping to ensure that funding of the HIVIAIDS program can be sustained.

Taking into account the new eligibility criteria for funding from the Global Fund alone, the share of domestic financing would increase to at least 50 percent of total spending over the next few years. This comes in addition to the increasing total cost of the national response to HIVIAIDS. Given the context of scarce fiscal resources, all demands for additional funding will need to be well founded. To this end, the analysis presented in this report provides insights regarding the drivers of the costs of the national response to HIVIAIDS (in terms of the dynamics of HIV infections, and the link between HIV infections and the demand for HIVIAIDS-related services), and the cost-effectiveness of HIVIAIDS interventions.

HIVIAIDS spending in the health sector (largely treatment cost) is projected to remain at about two to three percent of public health spending, which appears a sensible amount given the burden of disease (accounting for nine percent of all deaths in 2005/10 and for 24 percent of those aged between 15 and 59 years). More specifically, the annual cost of providing treatment-which represents about 10 percent of GDP per capita for first-line treatment and 20 percent for second-line treatment-falls well within a range that would normally be supported by the public health system. 
An additional consideration for policy makers to take into account is access to health services. The Jamaica Survey of Living Conditions 2009 points to the presence of social barriers in access to health services, both in terms of utilizing services and in the financial consequences of seeking care. HIVIAIDS, as a persistent and expensive health condition, potentially exacerbates such inequities.

In summary, the rationale for sustaining broad access to treatment through the public health system appears sound from a fiscal and public health perspective (even before taking into account the social repercussions).

The study also offers tools to assess the epidemiological as well as the financial consequences of investments in prevention. It finds that there are large differences in the risk, and therefore cost, of onward, additional infections across population groups. Specifically, because of the disease dynamics, the cost caused by an additional infection (and saved by an infection prevented) is significantly higher for mostat-risk populations, such as men who have sex with men and female sex workers. To improve the cost-effectiveness of prevention efforts, investments in prevention will need to be tested against these cost savings - in addition to the health outcomes.
To ensure the sustainability of the national HIV response, the study points to three priority areas for the Government:

- Develop a long-term sustainability plan with different financing options that defines the roles of different national agencies (as well as donor agencies). This plan would build on the cost estimates from this study as well as a public expenditure review to quantify government health spending.

- Assess the efficiency of funding allocations in the national response to HIV/AIDS, taking into account not only the immediate health consequences but also the epidemiological and financial repercussions of alternative HIVIAIDS interventions.

- $\quad$ Assess the allocative efficiency between prevention and treatment, and between specific programs within prevention, to guide targeted prevention efforts, particularly for most at risk populations; effective prevention in the short term will result in lower spending on treatment in the long term. 


\section{Introduction}

Jamaica faces increasing financing needs over the coming years to respond to its HIVIAIDS epidemic, largely reflecting the increased need for treatment. At the same time, the financing of its national HIV/ AIDS response has come under pressure from a domestic fiscal adjustment as well as from shrinking external resources. The response in Jamaica is currently financed by the Government of Jamaica and from other sources, such as the World Bank, the Global Fund to Fight AIDS, Tuberculosis and Malaria (Global Fund) and the United States Government. Due to the high level of public debt and the repercussions of the global financial crisis, the availability of domestic resources is and will continue to be very tight. It is expected that during the next two years external financing will cease or be significantly reduced, resulting in a need for a substantial increase in domestic financing for the country's HIVIAIDS response. Any shortfall in financing - whether domestic, external or both-will have serious implications for the delivery of HIV services.

The objectives of the study are to:

- Review current spending on HIVIAIDS and the sources of financing (domestic and external).

- Estimate the fiscal burden of the national HIVIAIDS response and assess the outlook for external financing of the HIV program.

- Project how the epidemic will unfold as well as what the costs would be under different scenarios.

- Provide recommendations to inform policy decisions.

To meet these objectives, the assessment utilizes an epidemiological model to project the number of new infections; a costing framework to project the cost of the national response and an economic framework to translate the number of new infections to fiscal costs. This report provides an assessment of and guidance on the financial sustainability of Jamaica's national response to HIV/AIDS. The analysis is organized in four major sections:

- Section II describes the state of the epidemic and of the national response. It summarizes the available data on the state and course of the epidemic thus far; discusses the evolving national response, and its costs and financing; and reviews the state of public finance and overall trends in health financing and access to health services 
- $\quad$ Section III projects the state of the epidemic and the costs of the national response from 2010 to 2030. The uncertainties regarding the demand for HIVIAIDS services and the consequences of the National HIVIAIDS Strategic Plan (NSP) being developed are illustrated by way of three envisaged scenarios: (1) A scenario with declining HIV incidence, broadly in line with the NSP; (2) a scenario with constant HIVIAIDS incidence; and (3) a scenario with increasing HIV incidence, which could result from a reversal of recent gains or as a consequence of ineffective prevention programs.

- $\quad$ Sections IV and V analyze the links between HIV incidence and the costs of the national response. In particular, they develop an economic framework to assess the fiscal burden of HIVIAIDS and the cost-effectiveness and allocative effectiveness of HIV/ AIDS interventions. The assessment of the cost-effectiveness of HIV/AIDS interventions is complicated, because the demand for treatment and other HIVIAIDS services follows an HIV infection only with a long lag. This is because HIVIAIDS is a persistent health condition that requires treatment for a long period. In addition, an intervention may affect the disease dynamics, with effects spread over a long time. Section IV develops tools to assess the fiscal costs arising from one additional HIV infection (or the savings achieved by an infection prevented), Section $V$ uses these tools to assess the fiscal costs of the national response to HIVIAIDS.

- $\quad$ Section VI considers policy lessons and challenges. This relates to the implications of declining external funding for domestic funding needs, the cost-effectiveness of HIVIAIDS interventions, the allocative effectiveness of the HIVIAIDS program, and funding of the increasing demand for treatment.

Finally, the Conclusions provide key messages from the analysis and suggest priority next steps for the national HIVIAIDS response. 


\section{The State of HIV/AIDS and of the HIV/AIDS Response}

To prepare the ground for the financial analysis, the present section describes the background of the evolving national response to HIVIAIDS. This is provided in two parts:

- The state of the epidemic: this reviews the epidemic thus far-including the latest evidence on the current state of the epidemic and the drivers of HIV incidence.

- Costs and the financing of the national response to HIVIAIDS: an estimate of the costs of financing the evolving national response to HIV/AIDS. Included in this subsection are two boxes, which describe:

- The macroeconomic and fiscal context, in Box 1.

- Overall health spending and access to health services across the population, in Box 2.

\section{The State of the Epidemic}

The estimated HIV prevalence rate in Jamaica is 1.7 percent among the adult population (aged 15-49 years). Higher prevalence rates are reported for the most-at-risk populations (32 percent among men who have sex with men and five percent among commercial sex workers).

According to the Ministry of Health, HIV incidence attained a peak of 5,500 new infections among adults and children in 1994 (Figure 1a) and subsequently declined to about 2,500 by 2005, and continued to decline (but more slowly) until 2010.1 AIDS mortality increased later and more gradually than HIV incidence, peaking at about 3,300 deaths in 2004. Around this year, the scaling-up of antiretroviral treatment also took off (from 180 persons receiving treatment in 2004 to 8,150 persons in 2010), which contributed to a steep decline in AIDS mortality to 1,800 deaths by 2010. It should be noted, however, that these estimates are subject to considerable uncertainty; they are generated by models with the result that people known to be HIV-positive account for only a subset of people living with HIV/AIDS and direct observations on HIV incidence are unavailable.

${ }^{1}$ Estimates presented in this section have been made by the National HIVIAIDS Program, using the UNAIDS EPP model and Spectrum and were provided by Dr. Sharlene Jarrett. Earlier estimates of the state and course of the epidemic are reported in Duncan and others (2010). 


\section{Figure 1. The Course of the HIV Epidemic in Jamaica, 1980-2010}

Figure 1a. Jamaica: HIV Incidence and Deaths, 1980-2010

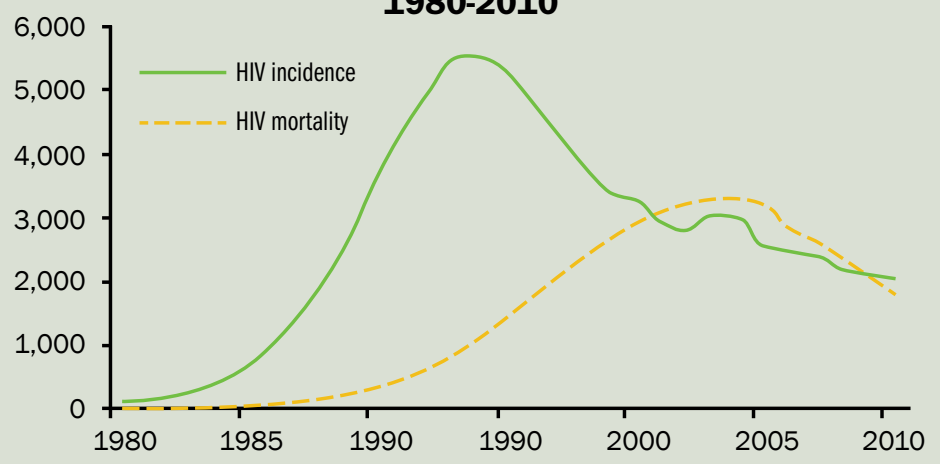

Source: Data provided by Minitry of Health/National HIV/AIDS Program

The number of people living with HIVIAIDS increased until about 2000 when it reached 37,000 (Figure 1b). The number then declined for a number of years, as increasing mortality among people living with HIV/ AIDS outstripped the number of new infections. After 2004, however, increasing access to treatment resulted in a steep decline in mortality. As a consequence, people receiving treatment account for an increasing share of people living with HIVIAIDS (rising to 27 percent by 2010). ${ }^{2}$

According to the Ministry of Health/Jamaica National HIV/STI Programme (MoH/NHP) (2010a), there were 378 AIDS deaths reported in 2009 (down from 692 in 2002), and about 900 new cases of HIV were reported for that year (down from about 1,200 annually in 2004-2006). ${ }^{3}$ As of the end of 2010, there were 7,560 adults (and 487 children) receiving antiretroviral treatment, corresponding to an antiretroviral treatment coverage rate among adults of 56 percent. ${ }^{4}$ Duncan and others (2010) estimate that about one quarter of people living with HIVIAIDS are men who have sex with men, three percent are female sex workers, five percent are male clients of sex workers, 0.6 percent are crack/cocaine users, 0.4 percent are prison inmates, 36 percent are "remaining males," and 30 percent are "remaining females."

The principal drivers of the HIV epidemic have been multiple partnerships, early sexual debut, high levels of transactional sex and inadequate condom use (MoH/NHP (2010b)). According to the 2008 "HIV/AIDS Knowledge Attitudes and Behavior Survey" (Hope Enterprises, 2008), 53 percent of males and 21 percent of females engaged in transactional sex, and the rate of condom use in this group was around 60 percent. Of respondents to the survey, 39 percent reported having multiple partners in the last 12 months (62 percent of males, and 17 percent of females). Twenty percent of male respondents, and 34 percent of female respondents knew their HIV status (i.e., received an HIV test in the last 12 months and knew the results). ${ }^{5}$ Among persons living with HIVIAIDS, 23 percent reported having sex with a sex worker, and more than 80 percent reported multiple partners (MoH/NHP (2010b)).

The impact of HIVIAIDS is reflected in recent trends in summary health indicators (Table 1). HIVIAIDS has reduced life expectancy at birth by 1.6 years (2.1 years for males, 1.0 years for females) as of 2005-10. This is a substantial reversal. Between 1955-60 and 2005-10, life expectancy grew at an average rate of 0.2 years annually. The impact of HIVIAIDS is therefore equivalent to a reversal of health gains in
Figure 1b. Jamaica: People Living with HIV/AIDS 1980-2010

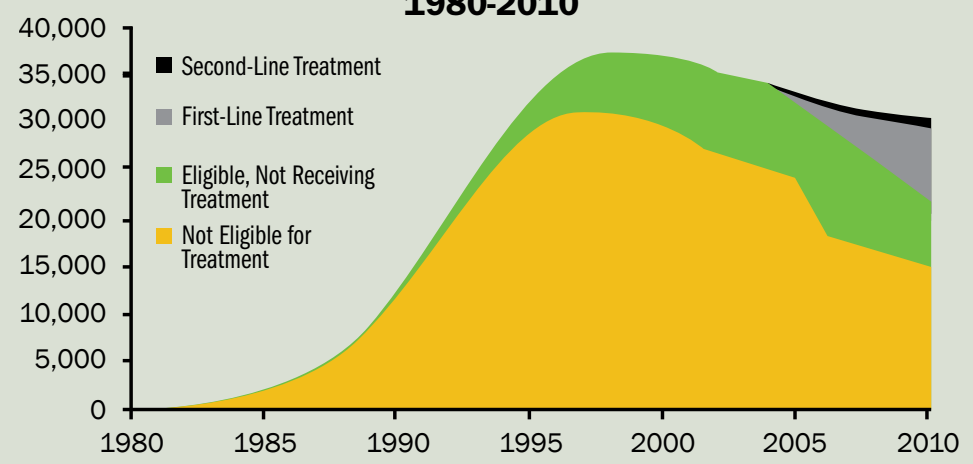

Source: Data provided by Minitry of Health/National HIV/AIDS Program

other areas achieved over eight years. HIVIAIDS-related mortality is concentrated among the adult population-HIV/AIDS accounted for about nine percent of all deaths in 2005-10, but only 1.5 percent of infant deaths.

Figure 2 provides an analysis of the contribution of HIVIAIDS to the burden of disease. For the overall population (Figure 2a), non-communicable diseases are the dominant cause of mortality, accounting for over two-thirds of deaths. Within this category, cardiovascular diseases account for 32 percent of total deaths. HIVIAIDS (eight percent of all deaths) accounts for almost one-half of all deaths from communicable diseases (17 percent). Owing to the age profile of HIV/ AIDS-related deaths, population averages mask somewhat the health consequences of the epidemic. This is evident from Figure $2 \mathrm{~b}$, which shows the main contributors to mortality for the 15-59 population. Here, HIVIAIDS accounts for almost one-quarter of deaths.

These summary indicators of health outcomes also offer some insights on the consequences of the scaling-up of treatment. According to UN$\operatorname{AIDS}(2010 a, b)$, the number of AIDS deaths has dropped from 2,600 in 2005 to 1,200 in 2009, largely as a consequence of improved access to treatment. This represents a decline in crude mortality among the population overall from 0.81 percent to 0.75 percent (with the share from HIVIAIDS declining from 12 percent to six percent) with a decline

${ }^{2}$ In Fig. 1b, the discontinuity in the numbers of people not eligible for treatment (based on current treatment guidelines) and of those eligible but not receiving treatment between 2005 and 2006 reflects a shift in eligibility criteria for treatment incorporated in the estimates by the Ministry of Health/ National HIV/STI Program (MoH/NHP)—from a CD4 count below 200 to a CD4 count below 350 .

${ }^{3}$ The reported number of people living with HIVIAIDS in 2009 is lower than the estimated number of people living with HIVIAIDS, as many people living with HIVIAIDS may not know their status, and not all HIV cases are reported. ${ }^{4}$ According to the draft National HIVIAIDS Strategic Plan.

5 The 2012 "HIVIAIDS Knowledge Attitudes and Behavior Survey" had not been released at the time of writing, but preliminary findings were reported by MoH/NHP (2012). According to these findings, the number of people reporting sexual intercourse with more than one partner in the past 12 months had declined to 28.1 percent; among these, 56.9 percent reported use of a condom at their last sexual intercourse. The reported percentage of women and men aged 15-49 "who received an HIV test in the past 12 months and know their results" had increased steeply to 58.7 percent ( 47.2 percent for men, 67.7 percent for women) 


\section{Figure 2. Mortality by Cause, 2008}

Figure 2a. Jamaica: Composition of Mortality, 2008

(All Ages)

\section{Figure 2b. Jamaica: Composition of Mortality, 2008 \\ (Ages 15-59)}

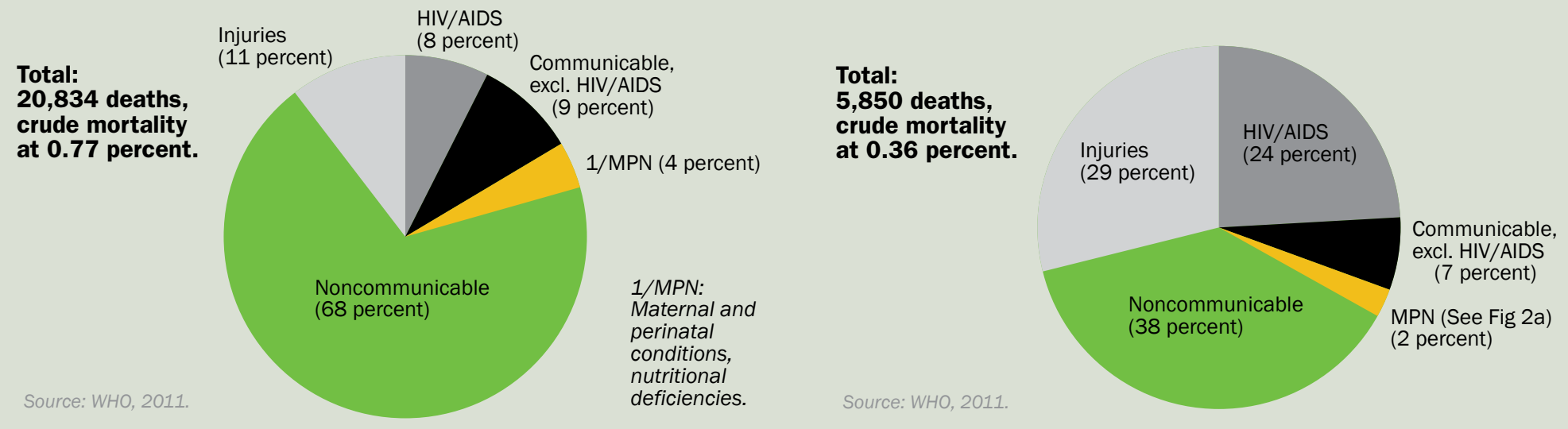

Table 1. Jamaica: Summary Health Indicators and Impact of HIV/AIDS

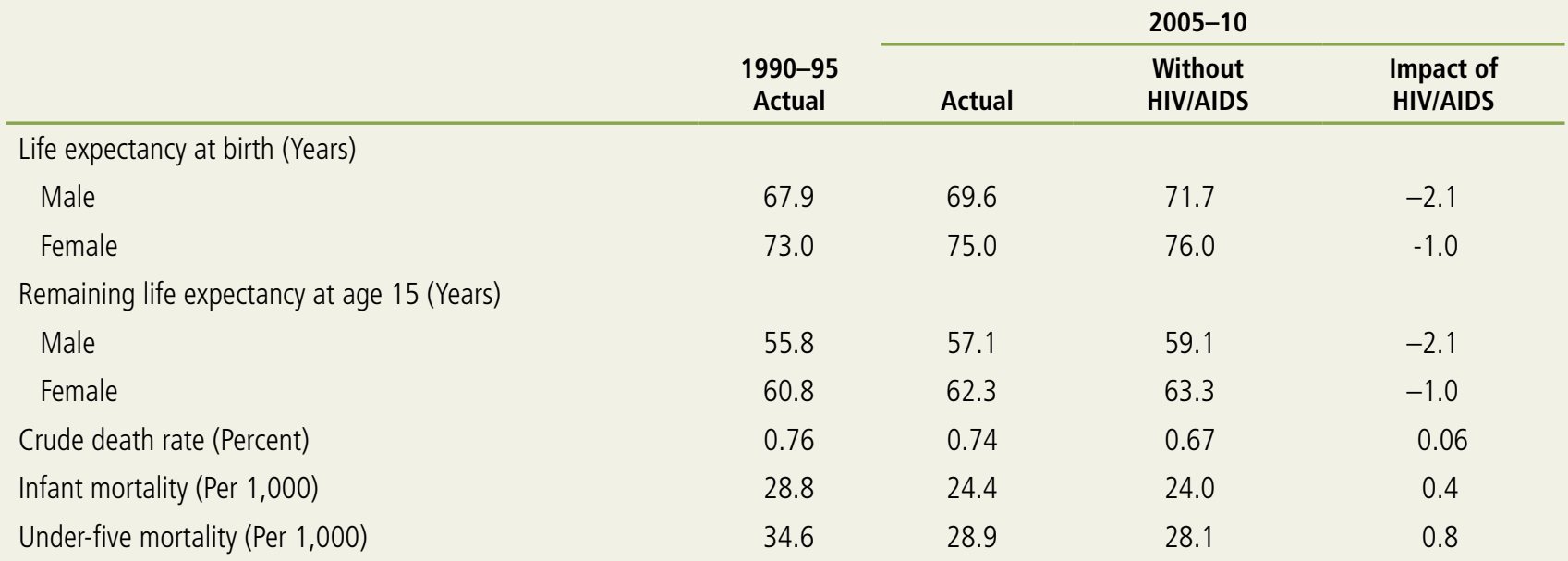

Source: United Nations Population Division, 2011. The impact of HIVIAIDS relates to the estimates for 2005-10. Estimates of actual health indicators for 1990-95 already reflect impact of HIVIAIDS.

in mortality of those between ages 15 and 59 years from 0.42 to 0.34 (with the share from HIVIAIDS declining from 36 percent 20 percent).

AIDS-related mortality is highly concentrated among mid-age adults (Figure 3). In the case of males between ages 30 and 45 years, HIVI AIDS is the dominant cause of death (Fig. 3a)-double the mortal- ity of a scenario without AIDS. The impact on women is less pronounced-HIVIAIDS increases mortality by about two-thirds between ages 30 and 39 years. As a consequence of increased premature mortality, survival to older ages declines; for example, the probability of reaching age 50 declines by five percentage points for males, and two percentage points for females.

\section{Costs and the Financing of the National Response to HIV/AIDS}

The national response to HIVIAIDS took off in 1988 when the National AIDS Committee was established and the first national HIV plan was introduced. ${ }^{6}$ The response is managed by the National HIV/STI Programme in the Ministry of Health, which is also the counterpart for funding from major donors. The national response to HIVIAIDS has significantly benefitted from external financing, notably from the World Bank (two projects approved in 2001 and 2008) and the Global Fund (2004 and 2008). External financing was instrumental in expanding prevention programs and extending access to antiretroviral treatment through public health services. (See also the discussion on HIV/AIDS spending and financing below.) Currently, the national re- sponse is guided by the "HIV and AIDS in Jamaica: NSP 2007-2012" (Government of Jamaica, 2008). A new NSP for 2013-18 is being prepared, but has not been finalized yet.

Notable achievements of the national response to HIVIAIDS include behavioral changes such as increased condom use, the expansion in treatment under the public access treatment program supported pri-

\footnotetext{
${ }^{6}$ See Figueroa and others (2008) for a comprehensive discussion of Jamaica's national response to HIVIAIDS.
} 
Figure 3. Mortality by Age and Sex, 2005-10

Figure 3a. Jamaica: Mortality by age and sex 2005-2010

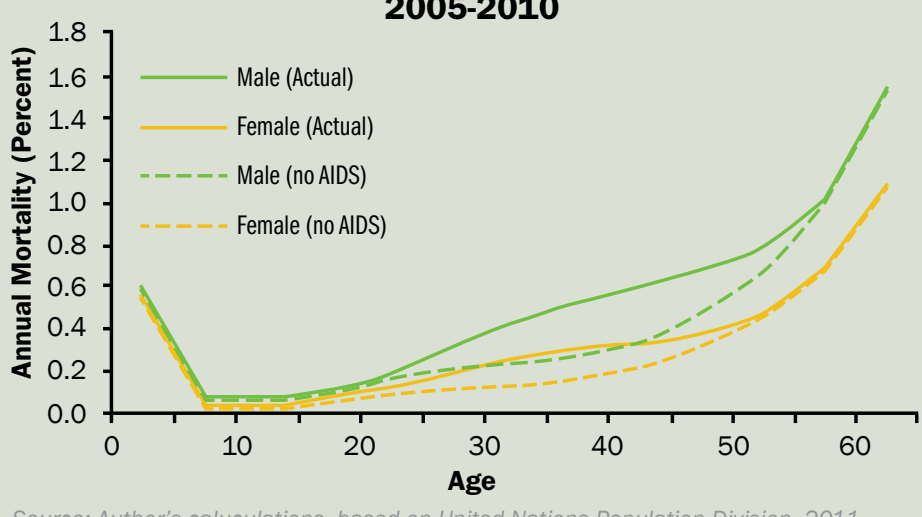

Source: Author's caluculations, based on United Nations Population Division, 2011.

\section{Figure 3b. Jamaica: Survival Rates from Age 0 by sex, 2005-2010}

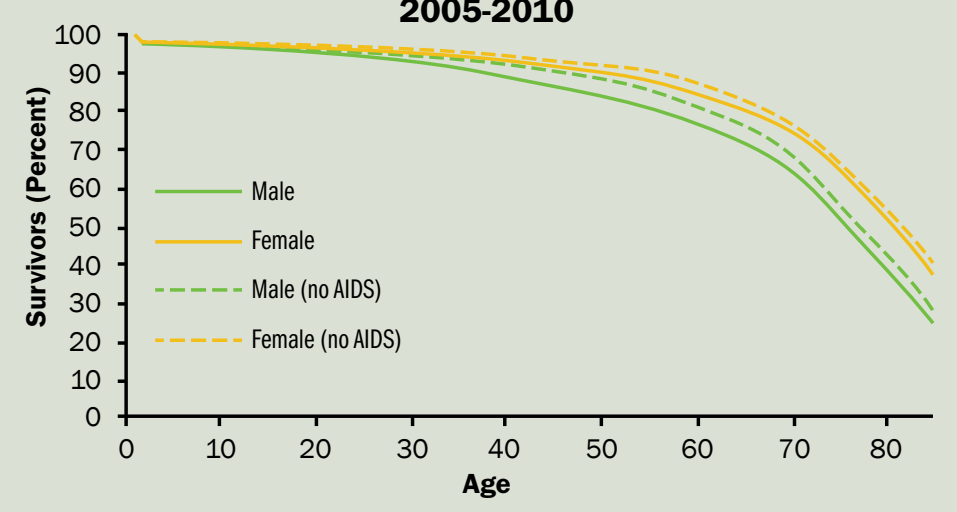

Source: Author's caluculations, based on United Nations Population Division, 2011. marily by the Global Fund, a considerable reduction in HIV prevalence among female sex workers (from 12 percent in 1989 to five percent in 2008), and increased access to and uptake of HIV testing. According to model-generated estimates by the Ministry of Health, HIV incidence has declined from a peak of over 5,000 HIV infections in 1995 to around 2,600 in 2002, and to 2,400 by 2010, while the rate of transmission of HIV from mother-to-child has declined from 25 percent before 2000 to less than five percent since 2007.

However, numerous challenges persist, that act as barriers to further reductions in HIV incidence. These include a lack of awareness of HIV status (close to 50 percent of people living with HIVIAIDS), the strong stigma against men who have sex with men combined with very high HIV prevalence in this population group (Duncan and others, 2010), and multiple partners and transactional sex in the general population (Figueroa and others (2008), Hope Enterprises (2008)). Consequently, most HIV infections now occur among men who have sex with men (53 percent, according to preliminary estimates of an ongoing study into modes-of-transmission) and their female partners (11 percent). The national response to HIVIAIDS has made little inroads so far in containing the spread of the epidemic among these population groups.

Data on the costs of the national response to HIVIAIDS were estimated based on information obtained from the following three sources:

- $\quad$ Actual spending recorded under the national response to HIV/ AIDS, as compiled by the National AIDS Spending Assessment (NASA) for the fiscal years 2009 and 2010.

- Data on unit costs of specific HIVIAIDS-related services, such as the estimates of the unit costs of treatment and related tests compiled by the Clinton Health Access Initiative.

- Data on government spending that does not directly target people living with HIVIAIDS or those affected by the epidemic but which addresses conditions related to both the impact of HIV/AIDS and to other factors. For example, HIVIAIDS results in higher mortality among young adults and increases the number of orphans and vulnerable children, but is not the only cause of children becoming orphans. In Jamaica, support for orphans and vulnerable children is provided by the Child Development Agency (CDA). As HIVIAIDS is a principal cause of children becoming orphans and for the need of social support among young people, it is appropriate to include part of the budget of the CDA under the costs of the national response to HIV/AIDS.

Estimates on the costs and sources of financing of the national response to HIVIAIDS are summarized in Table 2. From 2009/10 to 2010/11, the costs of the national response to HIV/AIDS increased from $\mathrm{J} \$ 1,681$ million (US\$ 19.3 million) to $\$$ 1,727 million (US\$20.4 million). More than two-thirds of total spending for the national HIV response was financed externally, notably through a grant from the Global Fund of J\$842 million (US\$ 10 million) in 2010/11 and a loan from the World Bank of J\$161 million (US\$ 1.9 million) in $2010 / 11.7$

HIVIAIDS spending financed from the national budget (J\$ 416 million in 2009/10 and $\$ \$ 535$ million in 2010/11) covers not only some of the operating costs of the NHP, but also the estimated costs of support for children affected by HIVIAIDS delivered through the CDA and some of the costs of delivering HIVIAIDS services not captured in specific HIVIAIDS budget line items (human resources, facilities). The bulk of HIVIAIDS services were delivered through the public sector (77 percent and 74 percent of the total spending in 2009/10 and 2010/11, respectively) and through civil society organizations, while international agencies and private providers played a small role. Total HIV/AIDS spending was equivalent to 0.45 percent of public spending in 2010/11, and domestically financed HIVIAIDS spending absorbed 0.14 percent of public spending in that year.

Figure 4 shows the composition of national response HIVIAIDS spending in 2010/2011. The largest component of HIV/AIDS spending is prevention efforts (J\$ 676 million in 2009/10 and J\$ 625 million in 2010/11). A large share of prevention spending has been geared towards "communication for social and behavioural change" targeting the general or young population but the program also included measures targeting sex workers and their clients, men who have sex with men, and drug users (about I\$ 10 million-equivalent to US\$ 120,000-each in 2010/11).

\footnotetext{
7 The NASA shows spending supported by the World Bank of J\$207 million. This probably includes a contribution from the Government of Jamaica of $J \$$ 46 million, which is attributed to domestic financing here.
} 


\section{Box 1. Macroeconomic and Fiscal Context of the National Response to HIV/AIDS}

GDP per capita in Jamaica is estimated at about US\$ 5,400 in 2011 (IMF, 2011). Compared to other countries in the Caribbean with elevated levels of HIV prevalence, GDP per capita is on about the same level as in the Dominican Republic (US\$5,400), much lower than in The Bahamas (US\$ 23,200) and Trinidad and Tobago (US\$ 16,700), but much higher than in Haiti (US\$ 740). Economic growth has been low in recent years. Between 1997 and 2007, real GDP grew by an average annual rate of 1.4 percent, and real GDP per capita by 0.7 percent. Owing to the global financial crisis, GDP growth was negative in 2008-2010 and dropped to minus 3.0 percent in 2009. For the fiscal year 2011/12 (April to March), the Ministry of Finance estimates GDP growth at 1.3 percent (Phillips, 2012).

The fiscal situation is challenging. The Ministry of Finance and Planning estimates that public debt stood at 128 percent of GDP at the end of March 2012, of which external debt accounted for 58 percent of GDP (Phillips, 2012). Reflecting the high level of public debt, more than one-half of public expenditures were absorbed by debt service (interest and amortization) in 2010/11. The government intends to reduce the budget deficit (6.2 percent of GDP in 2011/12) to 3.8 percent of GDP in 2012/13 and aims at a balanced budget by 2015/16 (Phillips, 2012).

Table 2. Costs and Financing of Jamaica's National Response to HIV/AIDS

\begin{tabular}{|c|c|c|c|c|c|c|}
\hline & \multicolumn{3}{|c|}{$2009 / 10$} & \multicolumn{3}{|c|}{$2010 / 11$} \\
\hline & $\begin{array}{c}\text { J\$ } \\
\text { Omillions }\end{array}$ & $\begin{array}{c}\text { US\$ } \\
\text { millions }\end{array}$ & $\begin{array}{l}\% \text { of } \\
\text { Total }\end{array}$ & $\begin{array}{c}\text { J\$ } \\
\text { millions }\end{array}$ & $\begin{array}{c}\text { US\$ } \\
\text { millions }\end{array}$ & $\begin{array}{l}\% \text { of } \\
\text { Total }\end{array}$ \\
\hline Total & $1,680.6$ & 19.3 & 100.0 & $1,727.2$ & 20.4 & 100.0 \\
\hline \multicolumn{7}{|l|}{ By source } \\
\hline Government of Jamaica & 416.0 & 4.8 & 24.8 & 535.0 & 6.3 & 31.0 \\
\hline HIVIAIDS spending & 173.6 & 2.0 & 10.3 & 259.1 & 3.1 & 15.0 \\
\hline Share of CDA budget ${ }^{1}$ & 242.4 & 2.8 & 14.4 & 275.9 & 3.3 & 16.0 \\
\hline External sources & $1,260.5$ & 14.5 & 75.0 & $1,188.2$ & 14.0 & 68.8 \\
\hline o/w Global Fund grant & 868.8 & 10.0 & 51.7 & 842.1 & 10.0 & 48.8 \\
\hline o/w World Bank loan & 111.2 & 1.3 & 6.6 & 161.2 & 1.9 & 9.3 \\
\hline Private sources ${ }^{2}$ & 4.0 & 0.0 & 0.2 & 4.0 & 0.0 & 0.2 \\
\hline \multicolumn{7}{|l|}{ By provider } \\
\hline Public sector & $1,299.3$ & 15.0 & 77.3 & $1,283.3$ & 15.2 & 74.3 \\
\hline International agencies & 65.4 & 0.8 & 3.9 & 28.4 & 0.3 & 1.6 \\
\hline Civil Society & 300.5 & 3.5 & 17.9 & 386.4 & 4.6 & 22.4 \\
\hline Private & 15.4 & 0.2 & 0.9 & 29.0 & 0.3 & 1.7 \\
\hline \multicolumn{7}{|l|}{ By spending category } \\
\hline Prevention & 675.7 & 7.8 & 40.2 & 625.4 & 7.4 & 36.2 \\
\hline Treatment, care, and support & 411.5 & 4.7 & 24.5 & 469.0 & 5.5 & 27.2 \\
\hline o/w: Antiretroviral therapy & 257.2 & 3.0 & 15.3 & 334.2 & 3.9 & 19.3 \\
\hline Social mitigation & 251.8 & 2.9 & 15.0 & 295.0 & 3.5 & 17.1 \\
\hline Program management & 341.5 & 3.9 & 20.3 & 337.8 & 4.0 & 19.6 \\
\hline Memorandum items & (In units indicated) & & & (In units indicated) & & \\
\hline Total costs (percent of GDP) & 0.15 & & & 0.14 & & \\
\hline Total costs (percent of public expenditures) ${ }^{3}$ & 0.40 & & & 0.45 & & \\
\hline $\begin{array}{l}\text { Domestically financed HIVIAIDS spending } \\
\text { (percent of public expenditures) })^{3}\end{array}$ & 0.10 & & & 0.14 & & \\
\hline Total costs (percent of public health exp.) ${ }^{3}$ & 5.5 & & & 7.2 & & \\
\hline \multicolumn{7}{|l|}{ Treatment, cane and support } \\
\hline (percent of public health exp.) $)^{3}$ & 1.4 & & & 2.0 & & \\
\hline $\begin{array}{l}\text { Source: Preliminary NASA estimates and author's } \\
1 \text { Share of budget of Child Development Agency } \\
2 \text { Private donations to national HIV/AIDS program } \\
{ }^{3} \text { Not all HIVIAIDS spending is included in public a }\end{array}$ & $\begin{array}{l}\text { timates. } \\
\text { DA), in line with estim }\end{array}$ & ed burden & HIVIAIDS. & & & \\
\hline
\end{tabular}




\section{Box 2. Health Spending and Access to Health Services}

Total health spending accounted for about 5.1 percent of GDP in 2009 (see box figure), equivalent to US\$228 per capita. The most recent increase in public health spending partly reflects the abolition of user fees in 2008. Private health spending (in relation to GDP) has increased since 2005 (and may have increased faster in real terms). The costs of health services in the consumer price index have increased at a much lower annual rate (about four percent) than overall inflation (about 14 percent) between 2006 and 2010.

However, health spending and access to health services is not distributed evenly across the population. Health spending increases more than proportionally with income (see box table), and the data reported

\section{Jamaica: Health Expenditures by Source of Funding, 1995-2009 (Percent of GDP)}

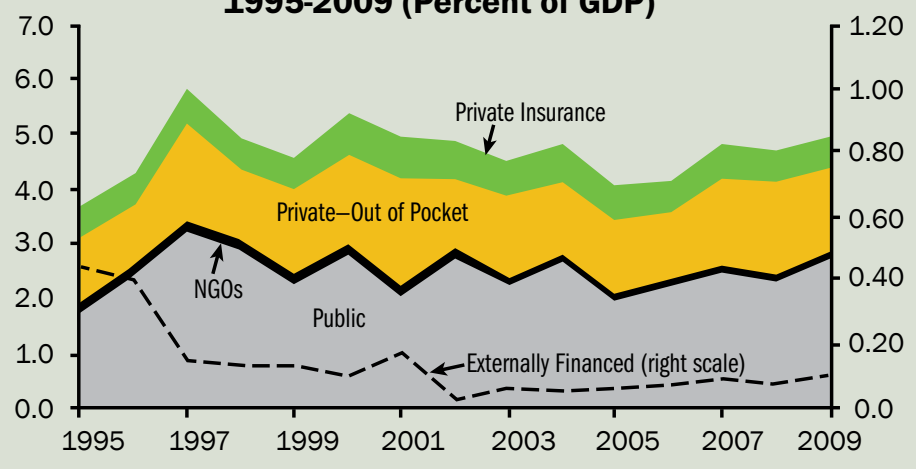

Source: WHO (2011). by STATIN and PIOJ (2010) also suggest an urban/ rural divide. Access to health insurance is higher in the richest quintile than in the poorest quintile (20.8 percent vs. 13.6 percent). Care-seeking poor households predominantly rely on public health facilities (63 percent), while the wealthiest households rely on private providers (76.6 percent)

Health Spending and Health Seeking Across Population Groups, 2009

\begin{tabular}{|c|c|c|c|c|c|c|c|}
\hline & \multicolumn{3}{|c|}{ Annual consumption per capita } & \multirow[b]{2}{*}{$\begin{array}{l}\text { Having health } \\
\text { insurance }\end{array}$} & \multirow[b]{2}{*}{$\begin{array}{l}\text { Reporting } \\
\text { illness }\end{array}$} & \multirow[b]{2}{*}{ Seeking care } & \multirow[b]{2}{*}{$\begin{array}{l}\text { Purchasing } \\
\text { medication }\end{array}$} \\
\hline & \multirow[b]{2}{*}{ Total J\$ } & \multicolumn{2}{|c|}{ Health } & & & & \\
\hline & & J\$ & $\%$ of total & $\%$ of indit & duals & $\%$ of ind. repe & g illness \\
\hline \multicolumn{8}{|c|}{ By Consumption Quintile } \\
\hline Poorest & 64,258 & 1,031 & 1.6 & 13.6 & 9.6 & 64.6 & 59.3 \\
\hline 2 & 106,240 & 2,175 & 2.0 & 16.3 & 11.9 & 71.7 & 72.8 \\
\hline 3 & 148,214 & 3,426 & 2.3 & 12.7 & 10.2 & 76.7 & 72.5 \\
\hline 4 & 206,917 & 4,695 & 2.3 & 16.9 & 10.9 & 77.6 & 70.4 \\
\hline Richest & 419,025 & 12,020 & 2.9 & 20.8 & 11.1 & 81.7 & 84.0 \\
\hline \multicolumn{8}{|l|}{ By Region } \\
\hline Kingston MA & 252,835 & 6,705 & 2.7 & 27.7 & 8.7 & 84.6 & 81.9 \\
\hline Other Urban & 232,136 & 5,993 & 2.6 & 22.2 & 10.2 & 82.8 & 79.3 \\
\hline Rural & 158,474 & 3,720 & 2.3 & 12.8 & 12.3 & 70.9 & 68.5 \\
\hline Jamaica & 205,693 & 5,201 & 2.5 & 19.8 & 10.6 & 77.1 & 74.4 \\
\hline \multicolumn{8}{|c|}{ Source: STATIN and PIOJ, 2010.} \\
\hline \multicolumn{8}{|c|}{$\begin{array}{l}\text { Available household data (STATIN and PIOJ, 2010) also point to differences in the economic consequences of injury or episodes of } \\
\text { illness across income groups. For poor households seeking care, the costs average at } 26 \text { percent of their monthly income per capita, } \\
\text { compared to nine percent for the wealthiest households. Similarly, the average costs of purchasing medication are } 29 \text { percent for the } \\
\text { poorest wealth quintile, but only } 10 \text { percent for the richest group. }\end{array}$} \\
\hline
\end{tabular}


Figure 4. Composition of Spending Under National

Response to HIV/AIDS, 2010/11 (Percent of total)

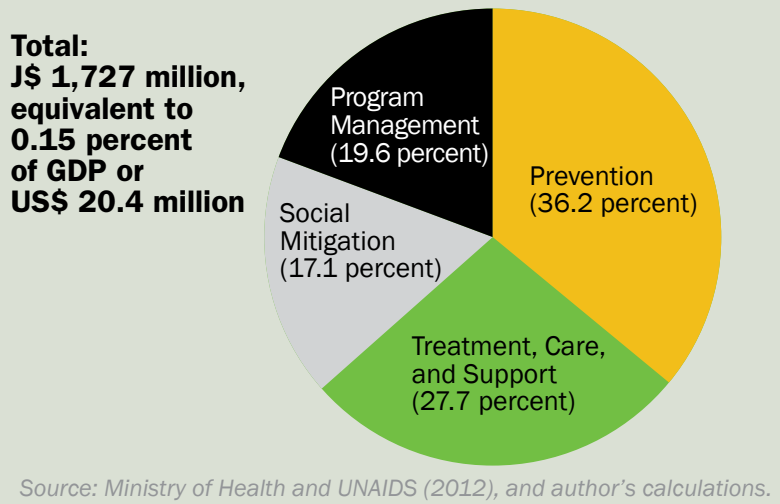

Treatment and care absorbed J\$ 411 million in 2009/10 and I\$ 469 million in 2010/11. The costs of providing antiretroviral therapy accounted for an increasing share of total spending (15 percent in 2009/10 and 19 percent in 2010/11). The estimated costs of treatment and care also include some provisions to capture the costs of health services other than antiretroviral therapy, which are not fully captured by recorded HIVIAIDS spending.
Social mitigation spending is dominated by the support given to orphans and vulnerable children through the CDA. The national response to HIVIAIDS also supports measures to create an "enabling environment" for people living with HIVIAIDS. Program management (including program administration and monitoring and evaluation) accounts for 20 percent of the costs of the national response to HIVIAIDS. 


\section{Projecting the Costs of the National Response to HIV/AIDS}

The following sections provide a forward-looking analysis (1) to quantify the fiscal costs of HIVIAIDS and of the national response to it (based on estimates of the state and course of the epidemic and on the objectives and targets of the national response); and building on that goal (2) to provide an analysis that supports decision making on policy and financing options in respect of the national HIVIAIDS program. To achieve these objectives, the current section provides projections of the costs of the national response to HIVIAIDS through 2030. The uncertainty about the course of the epidemic is reflected in three scenarios with different assumptions about the course of HIV incidence. The analysis includes:

- Epidemiological projections.

- Unit costs and coverage rates of HIV/AIDS services.

- Projected costs of the HIVIAIDS program, based on estimates and projections of the state of the epidemic, the coverage rates of HIVIAIDS services and unit costs of providing them.

- Some policy lessons.

In addition, the macroeconomic impact of HIVIAIDS is set out in Box 3.

\section{Epidemiological Projections}

The epidemiological projections are based on estimates and projections produced by the Ministry of Health, using the Spectrum package. An earlier version of these estimates is described by Duncan and others (2010). For the analysis offered in this report, the estimates were transformed into a spreadsheet-based model, to better capture the links between HIV incidence, program objectives, and the costs of the HIVIAIDS program.

The assumptions on the coverage rates of HIVIAIDS-related services are based on the NSP and the projections provided by the Ministry of Health. Most importantly, the coverage rate of antiretroviral treatment is assumed to rise from 73 percent of people newly requiring first-line treatment in 2011 to 90 percent of people newly requiring first-line treatment by 2015, and then to remain at this rate. 
Figure 5. People Living with HIV/AIDS, 2010-2030

\section{Figure 5a. People Living with HIV/AIDS (Ages 15+) 2010-2030 (declining HIV incidence)}

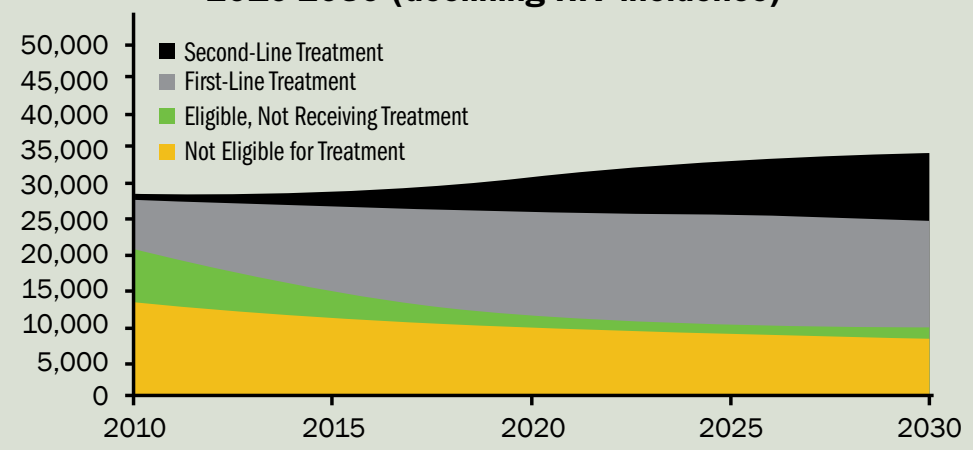

\section{Figure 5b. People Living with HIV/AIDS (Ages 15+) 2010-2030 (constant HIV incidence)}

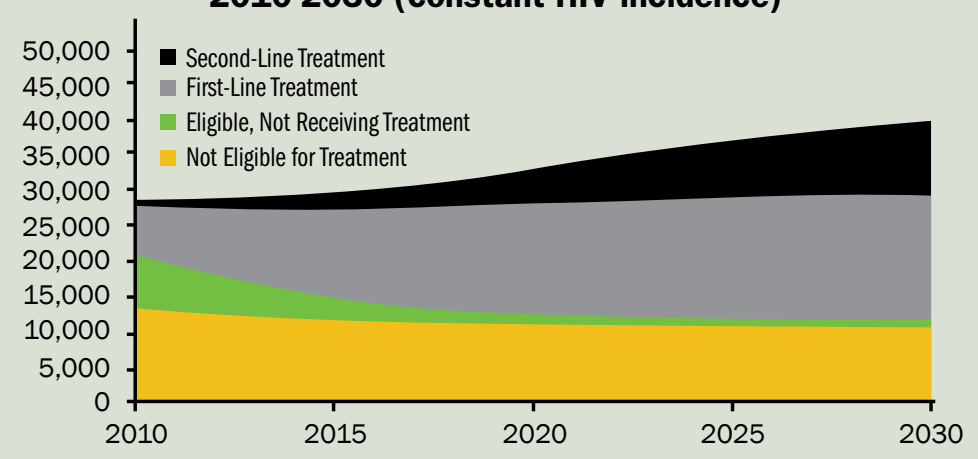

Figure 5c. People Living with HIV/AIDS (Ages 15+) 2010-2030 (increasing HIV incidence)

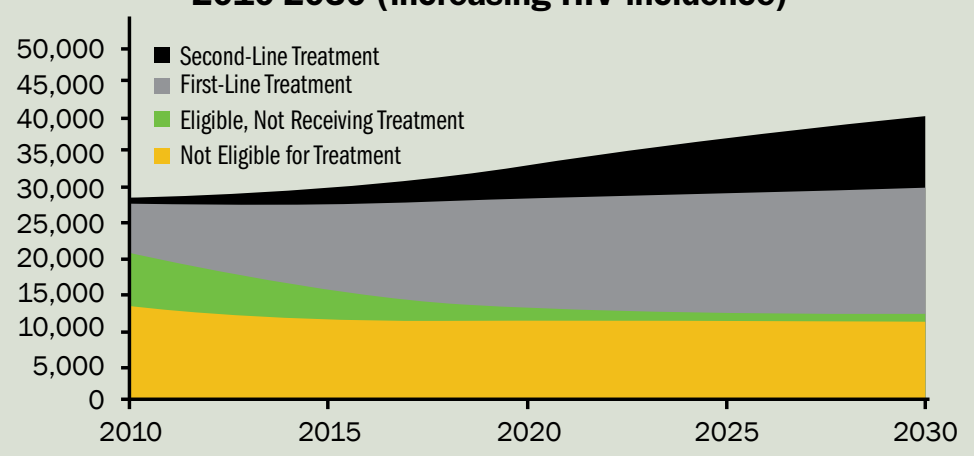

Source: Author's estimates and projections.
Ninety percent of people reaching the need for second-line treatment are assumed to initiate it. ${ }^{8}$ Other important assumptions (detailed below) regard the number of HIV tests conducted, access to services for the prevention of mother to child transmission of HIV, treatment of opportunistic infections, palliative care, inpatient care and support to children orphaned by HIV/AIDS.

The uncertainty about the future course of the epidemic is reflected in the following three scenarios:

- Scenario 1 (declining HIV incidence): In this scenario (broadly modeled in line with the objectives of the draft $\mathrm{Na}$ tional Strategic Plan and based on the projections of the Ministry of Health), the number of new adult infections declines from 2,000 in 2010 to about 1,680 by 2018 (i.e., by 2.2 percent annually) and more slowly thereafter at one percent annually. The HIV incidence rate declines from 0.14 percent (ages 15-49 years) in 2010 to 0.11 percent in 2030.

- Scenario 2 (constant HIV incidence): The number of new infections remains constant at 2,000 from 2010. HIV incidence rates also remain broadly constant at about 0.14 percent, as the size of the population aged 15-49 years barely changes over the projection period (UNPD, 2011).

- Scenario 3 (increasing HIV incidence): The number of new infections increases from 2,000 in 2010 to 2,300 by 2018 and grows more slowly by one percent annually thereafter (to 2,600 or 0.19 percent of the population aged $15-49$ years by 2030). Such an increase may reflect a reversal in sexual risk behavior (as suggested by recent behavioral data) data or a reduction in funding for HIV prevention activities.

Figure 5 summarizes the projections of the course of the epidemic under the three scenarios. At first sight, these projections look fairly similar. The number of people living with HIV/AIDS increases to 34,000 in Scenario 1 (declining HIV incidence), to 39,500 in Scenario 2 (constant HIV incidence), and to 45,200 in Scenario 3 (increasing HIV incidence). The principal factor behind this increase is the rising number of people receiving treatment, increasing from 7,900 in 2010 to between 24,900 (Scenario 1) or 30,600 (Scenario 3).

To allow comparisons between the scenarios, Figure 6 shows projections across the scenarios of the number of new infections, the number of people living with HIVIAIDS not yet eligible for treatment (based on national treatment guidelines) and the number of people receiving treatment. The projected numbers of new infections (Figure 6a) diverge noticeably over the first few years, differing by up to 18 percent by 2015. This spread-representing a decline in infections in Scenario 1 relative to Scenario 3-subsequently grows to 30 percent (by 2020) and 43 percent (by 2030).

\footnotetext{
${ }^{8}$ A rate below 100 percent does not imply that patients reaching the need for second-line treatment are denied it; it also reflects loss to follow-up and to those whose treatment need is not diagnosed correctly.
} 
The changes in HIV incidence are-with a lag of a few yearsclosely reflected in the number of people not yet eligible for treatment (Figure 6b). ${ }^{9}$ Between 2010 and about 2015, the number of HIV-positive people not yet eligible for treatment declines in each of the scenarios because HIV incidence had been coming down before 2010 (compare Figure 1). Subsequently, the number of people not yet eligible for treatment follows the trends in HIV incidence shown in Figure 6a. By 2020, the difference in the number of people not yet eligible for treatment between Scenarios 1 and 3 reaches 21 percent, and rises to 38 percent by 2030 .

The number of people receiving treatment, however, barely differs across the scenarios for the first 10 years of projections (Figure $6 \mathrm{c}$ ). By 2020, the gap between Scenarios 1 and 3 reaches five percent. By 2030 , the gap rises to 19 percent, which is much smaller than the difference in the underlying trends in HIV incidence. This low variation reflects two factors - the long and variable time period between an HIV infection and the need for treatment, and the long survival rates among people receiving treatment.

For the analysis of the fiscal sustainability of Jamaica's HIVIAIDS program, two important outcomes arise from this analysis:

- $\quad$ Successful prevention measures do not result in reduced spending on HIV/AIDS services in the short term.

- However, effective prevention measures that result in a decline in HIV incidence Scenario 1 do have an effect on financial resource needs in the long-term. In Scenario 1 for example, the number of HIV-positive people not yet eligible for treatment is reduced by 38 percent by 2030 . As a consequence, fewer people will require treatment-and absorb fiscal resources - over the following years.

In closing this preliminary analysis, it is useful to point to some limitations of these scenarios. The emphasis is on the implications of more or less successful HIV prevention policies for the state of the epidemic and the financial costs of the national response to HIV/ AIDS, whereas other variables, notably access to treatment, is the same across the scenarios. This approach does not capture some of the possible interactions between treatment access and the success of prevention efforts. To attain a treatment coverage rate of 90 percent, it is necessary to reach widely into most-at-risk populations. In this sense, there is a complementarity between successful prevention efforts and attaining high treatment coverage.

Additionally, the analysis does not capture the potential implications of treatment access on the health consequences of HIV/AIDS and the state of the epidemic if the coverage target is not reached or sustained. A lower fiscal burden would then mask the deteriorating health consequences of HIVIAIDS. Additionally, improved treatment access and prevention outreach across population groups could feed back into HIV incidence through channels that could be assessed more explicitly.

${ }^{9}$ Following an HIV infection, individuals progress to treatment need (at a CD4 eligibility criterion of 350) after around 6 years.
Figure 6. State of Epidemic Across 3 Scenarios, 2010-2030

Figure 6a. New Adult HIV Infections, 2010-2030, 3 Scenarios

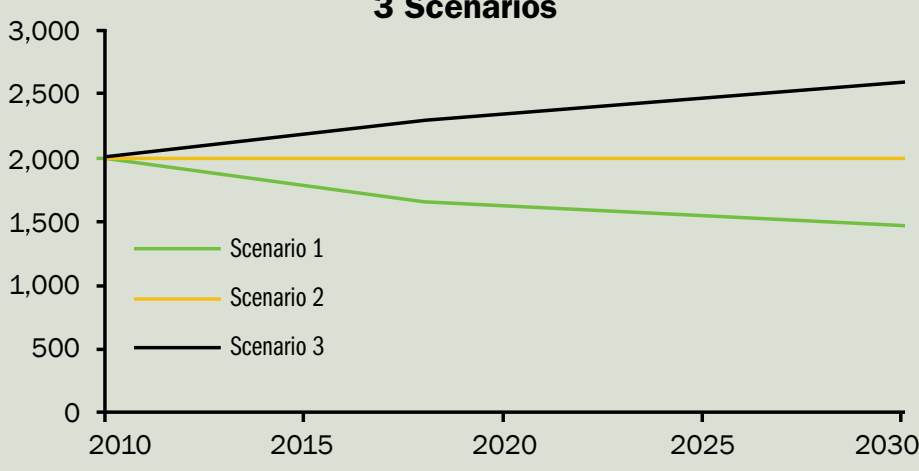

Figure 6b. HIV+ People Not Eligible for Treatment, 2010-2030, 3 Scenarios

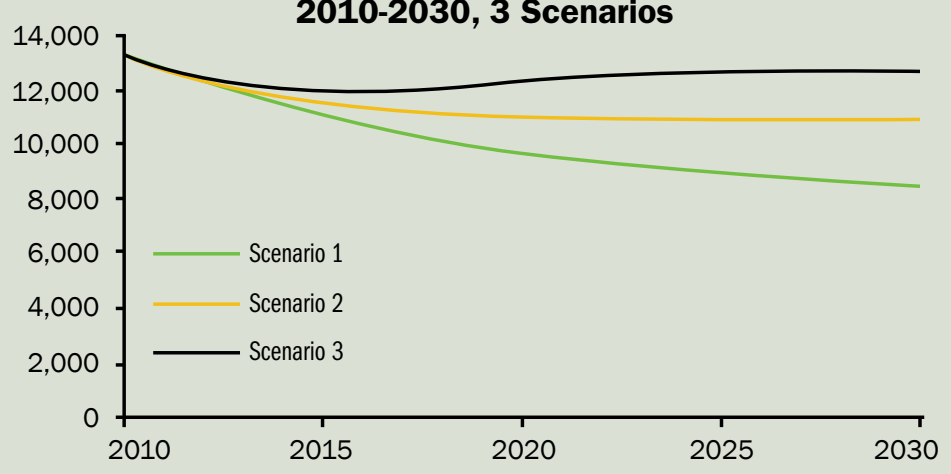

\section{Figure 6c. People Receiving Treatment 2010-2030 3 Scenarios}

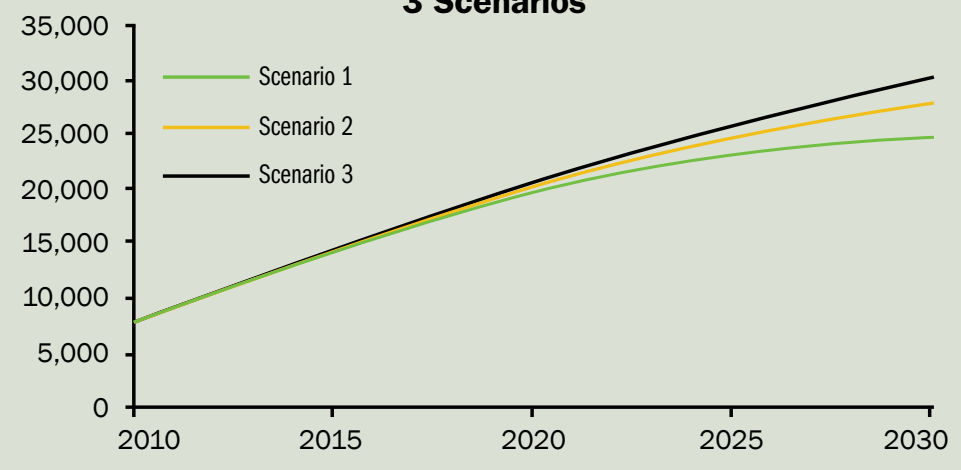

Source: Author's estimates. 


\section{Assumptions on Unit Costs and Coverage Rates} to HIV in 2009/10 and 2010/11 (above), the analysis of the costs of the national response to HIVIAIDS draws from data on actual HIV/ AIDS spending (as compiled in the NASA), estimates of the unit costs of providing certain HIVIAIDS services, and public spending that partly addresses the consequences of HIVIAIDS but is not captured by any specific HIV/AIDS budget line items. The most important assumptions underlying the projections are:

- Prevention. Data in the draft NSP suggest that about 300,000 HIV tests were conducted in 2010. Based on this, the projections assume that 15 percent of people aged 15-49 years received an HIV test in 2010 and that this share will increase to 20 percent by $2015 .^{10}$ Unit costs of HIV tests (J\$255) are based on local estimates provided by the Clinton Health Access Initiative. Additionally, an allowance for the costs of human resources and facilities (J \$ 425) has been included in the cost estimates. For the prevention of mother-to-child transmission (PMTCT) of $\mathrm{HIV}$, the coverage of screening was set at 95 percent, in line with the National Strategic Plan 2008-12. Based on Ministry of Health estimates and projections of the numbers of mothers receiving PMTCT, the coverage rate of PMTCT was set at 73 percent in 2010, rising to 95 percent by 2015 and remaining at that level. The costs of other prevention measures included in the projections are extrapolated from current spending and assumed to increase in line with population growth.

- Treatment and Care. The costs of antiretroviral treatment are based on local estimates provided by the Clinton Health Access
As explained in the discussion on the costs of the national response

Initiative, with the addition of allowances for the costs of human resources and facilities. For example, the annual costs of first-line treatment for adults were set at $\$ \$ 35,464$ as of 2012 , which comprises the costs of drugs $(J \$ 14,181)$, test kits $(J \$ 2,282)$ and human resources and facilities (J 19,000). The costs of drugs for adult second-line treatment were set at $\$$ 76,207. The costs of drugs for pediatric treatment were higher, at J\$18,526 for first-line treatment and $\mathbf{J} \$ 88,104$ for second-line treatment as of 2012. Additionally, allowances for the costs of non-antiretroviral treatment, palliative care, and inpatient care were included in the estimates, which items account for about 20 percent of the total costs of treatment and care.

- Social mitigation. The NASA identifies only a small amount of social mitigation spending. ${ }^{11}$ However, some social support provided by the government is not HIV-specific, even though the needs that are supported are partly caused by HIVIAIDS. Based on the assumption that one-half of the budget of the CDA is allocated to orphans and vulnerable children, an average annual cost of $\mathrm{J} \$ 10,741$ per orphan was included in the projections. ${ }^{12}$

- Administration of HIV program. Based on the NASA, the costs of operating the HIVIAIDS program, monitoring and evaluation, and all activities not included elsewhere, were set at 20 percent of the costs of prevention, treatment and care, and social mitigation.

- Change in costs over time. The costs of drugs and test kits remain constant. Most other services are intensive in human resources. Unit costs therefore rise in line with GDP per capita, to capture the effects of rising wages.

\section{Projected Costs of HIV/AIDS Program}

Based on the epidemiological projections (as well as underlying assumptions on the coverage rates of treatment and other HIVIAIDS services) and the estimates of unit costs, it is possible to project the future costs of the national response to HIV/AIDS. This analysis is intended to address two issues:

- $\quad$ Projected costs and funding needs. To appreciate the fiscal burden, evaluate program alternatives and consider financing options, it is necessary to understand how the costs of the HIVIAIDS program evolve

- Impact of prevention outcomes. To assess how epidemiological outcomes based on alternative assumptions on HIV incidence translate into spending needs

Figures 7 and 8 summarize the projections over the period 2010-30 (see also Appendix Table 1). In all scenarios, the costs rise steeply-from J\$ 1.7 billion in 2010 to between $\mathbf{\$} 3.1$ billion (Scenario 1) and $\$ 3.4$ billion (Scenario 3) in 2030 (in constant 2010 prices). As GDP is projected to increase over this period, the increase relative to GDP is less pronounced, with spending needs rising from 0.15 percent of GDP to between 0.20 percent of GDP and 0.22 percent of GDP. ${ }^{13}$
Almost all of this increase is accounted for by the increasing costs of treatment and care, rising from $J \$ 470$ million in 2010 to between

\footnotetext{
${ }^{10}$ Preliminary data from the 2012 "HIV Knowledge Attitudes and Behavior Survey," quoted by the Ministry of Health and the National HIV/STI Programme (2012), which show a steep increase in access to testing, suggest that this rate may have to be adjusted upwards.

${ }^{11}$ For example, in 2010/11, the NASA reports J 2.5 million for orphans and vulnerable children, $\mathbf{\$} 7.1$ million for "social protection through provision of social services," and I\$ 11.3 million for HIV-specific income generation projects.

12 The costs per orphan actually receiving care through public services are higher. In the absence of sufficient data about the number of orphans supported through the public sector, estimates are based on the average cost per orphan to the public sector (public spending on orphans, divided by total number of orphans in the country). The costs are then attributed to the national response to HIVIAIDS in line with the estimated share of children orphaned by HIVIAIDS among the total number of orphans.

${ }^{13}$ There is a small discrepancy in the costs relative GDP estimated here for 2010, and the estimates of HIVIAIDS spending reported above for fiscal year 2010/11. This discrepancy ( 0.15 percent of GDP vs. 0.14 percent of GDP) arises because the estimates and projections are set up on a calendar year basis, whereas the spending figures relate to the fiscal year.
} 
Figure 7. Cost of National Response to HIV/AIDS, 3 Scenarios, 2010-2030

Figure 7.1.a. Costs of National Response to HIV/AIDS 2010-2030 (declining HIV incidence)

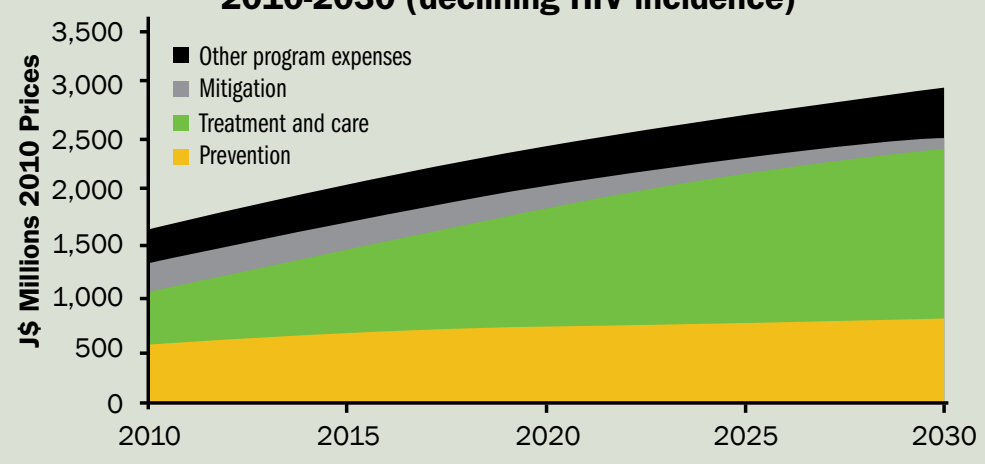

Figure 7.2.a. Costs of National Response to HIV/AIDS 2010-2030 (constant HIV incidence)

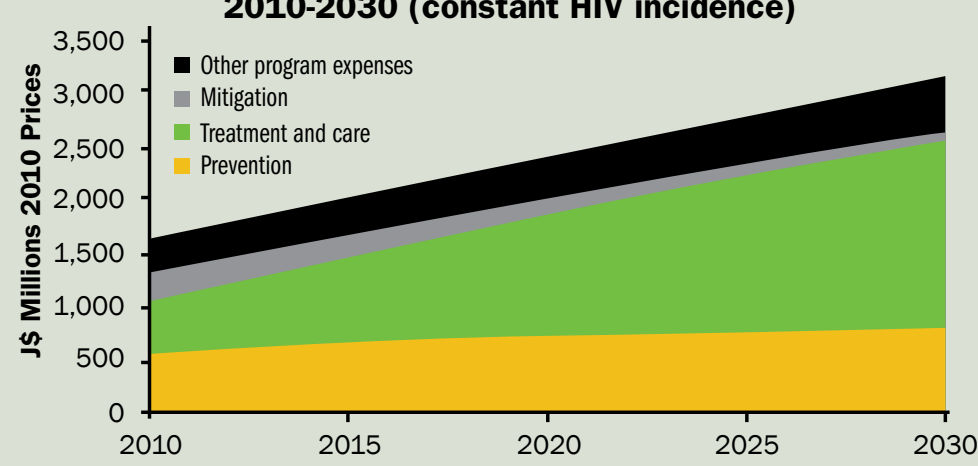

Figure 7.3.a. Costs of National Response to HIV/AIDS 2010-2030 (increasing HIV incidence)

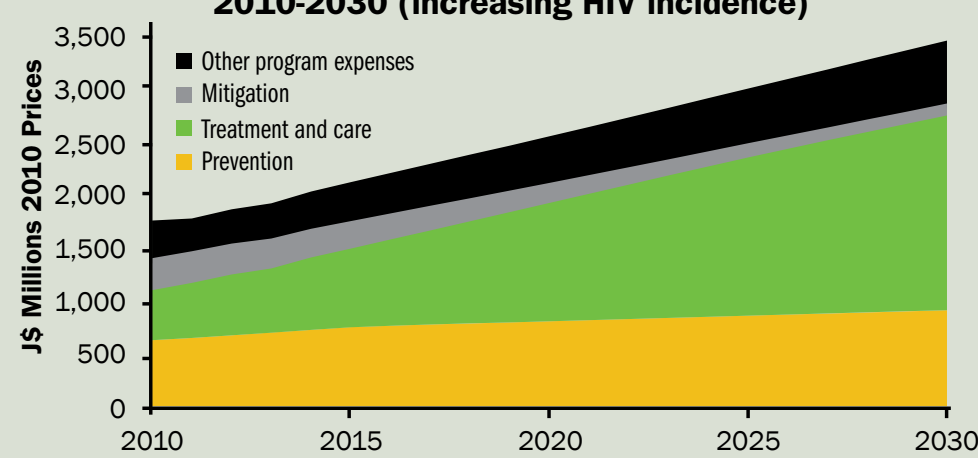

Figure 7.1.b. Costs of National Response to HIV/AIDS 2010-2030 (declining HIV incidence)

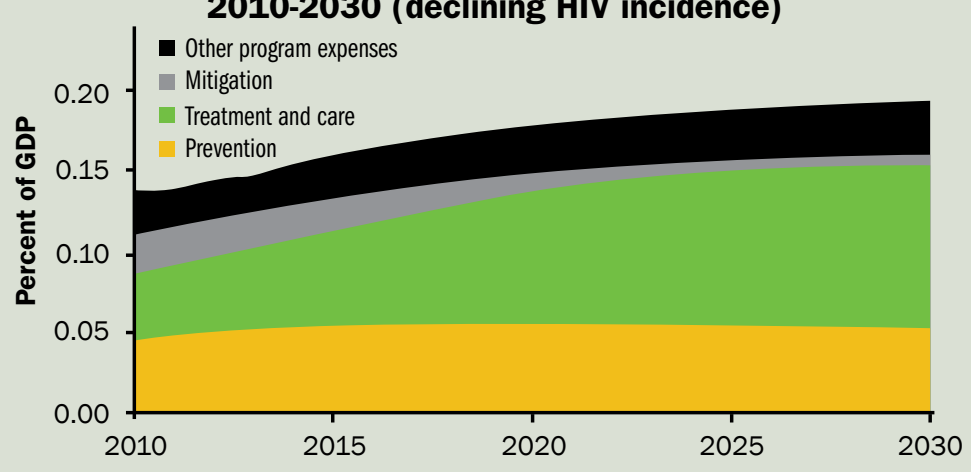

Figure 7.2.b. Costs of National Response to HIV/AIDS 2010-2030 (constant HIV incidence)

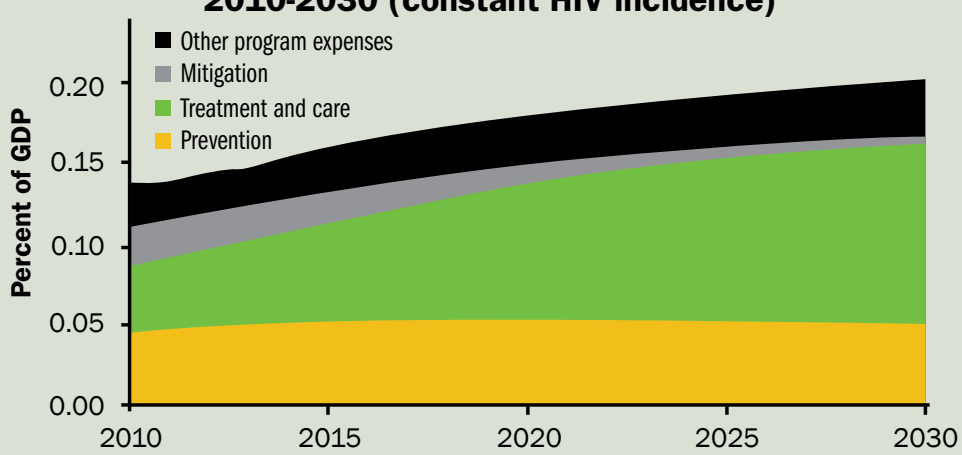

Figure 7.3.b. Costs of National Response to HIV/AIDS 2010-2030 (increasing HIV incidence)

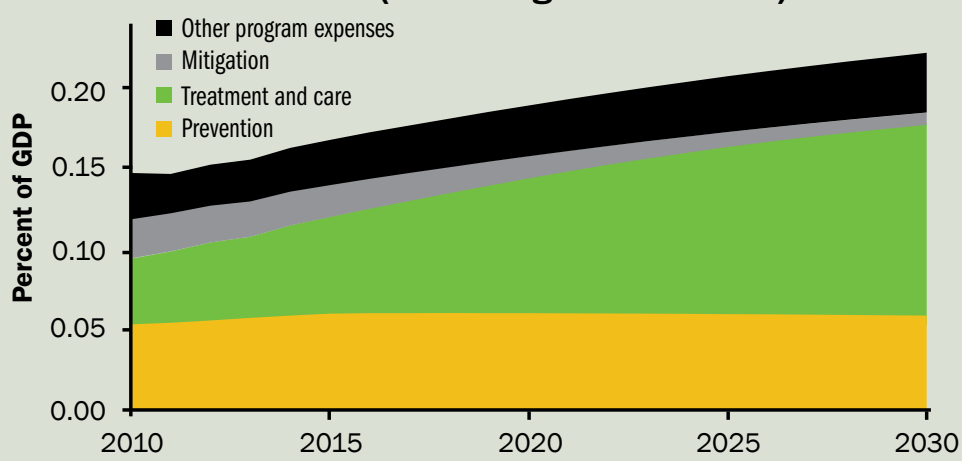


Figure 8. Costs of National Response to HIV/AIDS 2010-2030 (across scenarios)

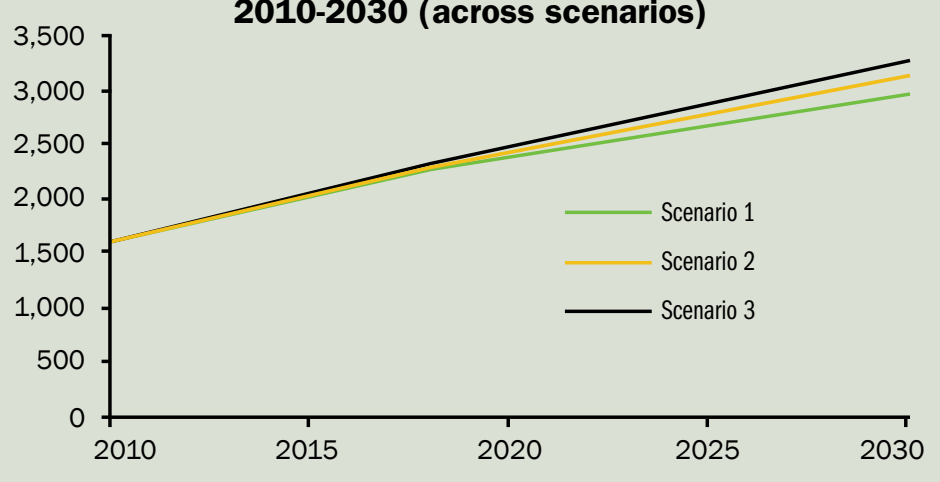

Source: Author's estimates.

J $\$ 1.5$ billion and $\$ \$ 1.8$ billion by 2030. The increase in the costs of treatment is steeper than the increase in the number of people receiving treatment, because an increasing share of people on treatment receives more expensive second-line treatment.

For example, in Scenario 1, the number of people receiving treatment rises from about 8,000 in 2010 (of which eight percent receive second-line treatment) to about 20,000 in 2020 (of which 24 percent are on second-line treatment) and to 25,000 in 2030 (of which 38 percent are on second-line treatment. Largely as a result of this composition effect, the average annual unit costs of antiretroviral treatment rise from $J \$ 42,400$ to $J \$ 59,200$ over this period, accounting for $J \$ 13,900$ of the total increase of $\$ \$ 16,800$ (with the balance reflecting increasing wage costs). ${ }^{14}$

Comparing the scenarios (Figure 8), the differences in costs are remarkably small — by 2030, the total costs of the national response to HIVIAIDS in the scenario with declining HIV incidence (which is broadly in line with the objectives of the draft NSP) are only 11 percent lower than for the scenario envisaging a substantial increase in HIV incidence. This difference is much smaller than the differences in the number of people receiving treatment (19 percent) or the number of new infections (43 percent). Nevertheless, the difference in costs of 11 percent between the two scenarios will not be insignificant when it actually comes to financing of the national HIV program.

This low variability reflects the long lag between HIV infections and treatment need. This applies, in particular, to the costs of second-line treatment, which become increasingly important over the projection period, and for which transition from infection (via first-line treatment) to the need for second-line treatment can take well over a decade. Additionally, it is assumed that prevention spending remains the same across scenarios, so that total spending changes less across scenarios than the costs of treatment.

14 In Scenario 3, with people receiving treatment increasing to 30,600 , the share of people receiving second-line treatment by 2030 is somewhat lower (34.4 percent). This is owing to the fact that many of the additional HIV infections in this Scenario occur relatively late, and many of the additional individuals infected do not proceed to second-line treatment by the end of the projection period.

\section{Box 3. Macroeconomic Impact of HIV/AIDS}

The economic framework applied in this study includes a macroeconomic model, for two reasons. First, the projections of the costs of the HIV program extend over two decades. To assess the magnitude of these costs it is necessary to take into account the fact that GDP (and the government's domestic revenues) is expected to increase substantially over this period. Second, the negative impact of HIV/AIDS on economic growth may undermine the government's capacities to finance the response to HIVIAIDS.

The macroeconomic projections utilize a simple neoclassical growth model. The projections on the growth of the working age population were obtained from UNPD (2011). Labor productivity is assumed to increase after 2016 at a rate of 1.5 percent annually; until then, the parameters are set to replicate growth projections from the IMF (2011b) and the savings rate is set at 20 percent, broadly in line with national accounts.

HIVIAIDS is assumed to affect GDP growth in several ways: (1) AIDS-related mortality affects productivity (one percent additional mortality reduces productivity by 0.5 percent); (2) HIVIAIDS slows down the growth of the working-age population; (3) increased spending on HIV/AIDS reduces national savings proportionally (at a savings rate of 20 percent, $\$$ \$ 1 million of additional HIV/AIDS spending crowds

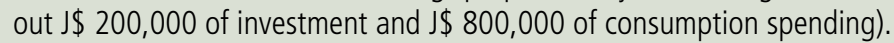

This model suggests that HIVIAIDS does have a small impact on GDP growth, largely because increased mortality reduces the growth rate of the working-age population and that the impact on GDP per capita is very small. The model predicts that GDP will be 2.8 percent smaller in 2030 than in the absence of HIVIAIDS. This is largely accounted for by the smaller size of the working-age population (minus 2.4 percent, due to the accumulated effect of higher mortality), whereas GDP per capita is reduced by 0.3 percent. 


\section{Some Policy Lessons}

There are a number of lessons for HIVIAIDS policies and the financing of the HIVIAIDS program that can be drawn from the analysis of the projected costs of the HIVIAIDS program, namely:

- The most important driver of the rising costs of the HIV program is the cost of treatment and, ultimately, the number of HIV infections. Treatment costs are a consequence of earlier HIV infections, although long lags occur between infection and need of treatment. To better understand the cost-effectiveness of HIV interventions, the next section will provide explicit estimates of the consequences of new HIV infections in terms of the resulting spending needs

- Improved prevention efforts reduce demand for HIVI AIDS services in the long-term, but do not provide a short-term fix to contain the funding needs of the HIV/ AIDS program. As the consequences of new HIV infectionsin terms of an increased demand for HIVIAIDS services-are spread over several decades, progress in reducing HIV incidence does not immediately reduce the costs of care, treatment, and social support.

- The projected costs, however, understate the differences in the fiscal consequences across scenarios. Spending in Scenario 1 (with declining HIV incidence) is only 11 percent lower in 2030 than in Scenario 3 (with an increase in HIV incidence). At that time, the number of HIV-positive people not yet eligible for treatment (based on treatment guidelines), but who are in line to initiate treatment over the next couple of years, is reduced by one-third (and the number of new infections by 43 percent). Therefore, spending commitments to serve this impending need are greatly reduced between these scenarios. The next section will provide tools to measure the fiscal consequences of alternative HIV/AIDS policies more precisely, taking into account these spending commitments. 


\section{HIV Incidence and the Costs of the HIV/AIDS Response}

The demand for HIVIAIDS services and the costs of the national response are ultimately driven by HIV infections, and a large share of the budget of the National HIVIAIDS Program is dedicated to HIV prevention efforts. The present section analyzes the link between HIV incidence and the costs of the HIVIAIDS program in three stages:

- The costs incurred by each additional HIV infection. These costs are estimated as the actuarially fair value of providing HIV/AIDS services to a person living with HIV/AIDS from the time of infection to the time of death, in line with the epidemiological model and treatment coverage rates targeted by the National HIV/AIDS Program.

- Cost-effectiveness of HIV prevention interventions. Based on the estimates of the costs incurred by an additional HIV infection, the cost-effectiveness of HIV prevention interventions can be assessed.

- Prevention policies and the drivers of HIV incidence. Each infection that is prevented means that an individual not infected will also not pass on HIV to. This aspect is particularly important among high-risk groups, where high-risk sexual behavior is also associated with a higher probability of onward transmission of HIV, including to people outside the respective risk group.

\section{The Costs Incurred by each Additional HIV Infection}

An HIV infection results over time in additional demand for HIV/AIDS-related services and the consequent additional fiscal costs of providing them in line with the objectives of the national response to HIVIAIDS. The overall costs of meeting the demand for HIVIAIDS services for all people living with HIVIAIDS were estimated in the previous section. The same framework can be used to estimate the costs that are incurred by one additional infection. Figure 9 shows such estimates, which were obtained by adding one HIV infection occurring in 2012 to the projections and calculating how this additional infection subsequently increases the demand for HIVIAIDS services and the costs of the national response to HIVIAIDS. ${ }^{15}$

15 The analysis proceeded in three steps: (1) the projected costs of the national response were recorded; (2) one additional HIV infection was added in 2012, and the new projected costs were obtained; and (3) the costs incurred by the additional HIV infection are obtained as the difference between the program-level costs obtained in steps (1) and (2). As the consequences of an HIV infection differ somewhat between males and females, the results shown are a weighted average of the costs incurred by an additional HIV infection among males and females, respectively. 
Figure 9. Jamaica: Costs of One Additional Infection, 2012

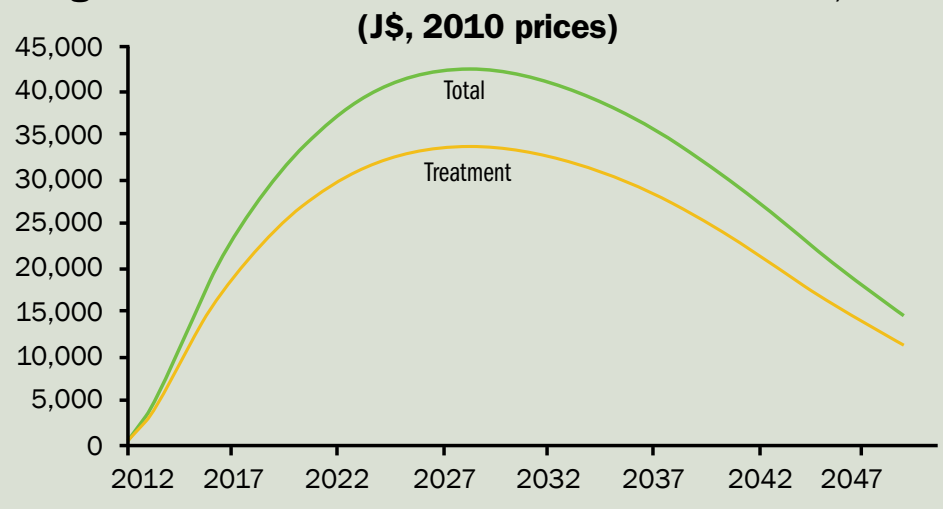

Source: Author's calculations.

The expected costs caused by an additional HIV infection in 2012 rise to about $\$ \$ 40,000$ annually over the 15 years following an infection. This build-up in costs is mainly accounted for by treatment costs, reflecting the increasing probability that the person will require and receive (first-line) treatment. While most people deemed eligible will receive treatment (assumed coverage rate of 90 percent), the expected costs are lower than the unit costs of treatment because of the high rate of emigration (especially in the age groups in which HIV incidence is also high), and because of the fact that the time from infection to the need for treatment differs across people living with HIVIAIDS. The other cost drivers are social mitigation (mainly orphan support) and the management of the HIV program (overhead).
After around 15 years, expected costs decline, primarily reflecting declining survival. At the same time, there is an increasing share of people receiving treatment who switch to more expensive medication, so that the average unit costs of treatment increase, and the expected costs caused by one infection decline over time more slowly than survival does. ${ }^{16}$

These costs incurred over time by an HIV infection are relevant for the assessment of the cost-effectiveness of HIV prevention interventions, as the costs of the prevention intervention are at least partly offset by the subsequent financial savings owing to the diminished need for HIV/AIDS-related services. This point is developed more fully in the next section.

\section{Assessing the Cost-Effectiveness of HIV Prevention Interventions}

It is challenging to assess the cost-effectiveness of HIV prevention interventions, because it is necessary to take into account the improved health outcomes, the costs of the intervention and the financial savings from the reduced demand for HIVIAIDS services which are spread over several decades (as discussed in the previous section). In order to establish the net costs of the intervention, i.e., the costs of the intervention minus the financial savings which result from it, the financial savings — which are spread over many years - need to be translated into an equivalent one-off amount to arrive at the actuarially fair value of the financial savings, namely the one-off amount that is equivalent to the savings occurring over time. Equivalently, it is the one-off amount that the government would need to set aside at the time of infection to pay for the costs of HIVIAIDS services of one patient during the course of the disease. As this one-off amount would yield interest until it is used to pay for HIVIAIDS services, it is necessary to discount the expected future costs at the interest rate relevant for the government. The actuarially fair value of the costs incurred by one infection (or savings from one infection prevented) is therefore obtained by adding up the discounted expected costs incurred by one infection over time.

For reasons explained in Box 4, the estimates offered here are based on an interest rate of five percent, which is at around the level of the real interest rate that the government pays for its public debt. At this interest rate, the estimated costs incurred by one HIV infection are equal to J $\$ 500,000$ (rounded to the nearest J\$1,000), or US\$5,800, roughly the level of GDP per capita.

This means that preventing one HIV infection at a cost of less than I\$ $\$ 500,000$ (US\$ 5,800) reduces the financial costs of the national response to HIVIAIDS - it is a good financial investment, even without taking into account the positive health effects. For an HIV infection averted at a higher cost, the net costs are obtained by subtracting the financial savings of $\$ \$ 500,000$ from the overall cost. For example, if an intervention prevents one HIV infection at a cost of $\$ \$ 600,000$, the health gains arrive at a net cost of $\$ \$ 100,000$, and if it costs less than $J \$ 500,000$, it saves money.

In many cases, the effects of an HIV intervention cannot be interpreted as an infection prevented forever, as the beneficiaries of a prevention intervention may contract HIV in the future. The estimates of the costs incurred by one additional infection can also be used in

\footnotetext{
${ }^{16}$ One important issue that this study does not cover in detail is the interaction between treatment access and the quality of HIVIAIDS-related services and disease progression. Improved management and delivery of treatment may prolong the duration of first-line treatment, and delay onset of treatment failure and transition to more expensive second-line treatment. Thus, there is a potential for improving survival rates, while reducing the expected costs of second-line treatment that is not explored in this report.
} 


\section{Box 4. Estimating the Financial Costs of New Infections}

The estimates of the cost incurred by new infections and the fiscal space committed by the HIV program used in this report are based on an actuarially fair estimate of the expected cost of meeting the demands for HIV/AIDS services caused by a new infection. This is the amount that the government would hypothetically agree to pay to some agency at the time an infection occurs to cover the cost of meeting the demand for HIVIAIDS services for that patient.

This actuarially fair estimate discounts future HIVIAIDS spending at the interest rate relevant for the government. As the cost projections are specified in real terms (at constant prices), the relevant interest rate is the real interest rate on public debt.

To calculate this actuarially fair estimate, it is necessary to choose the appropriate interest rate. The real interest rate on public debt has averaged 7.9 percent for debt denominated in Jamaican dollars and 4.1 percent for debt denominated in foreign-currencies- 5.8 percent overall. These averages may not be representative, however, as they include a spike in the domestic interest rate in 2009/10.

The projections offered in this report are based on a real interest of five percent. This might be too high if the fiscal situation improves and the risk premium on Jamaica's debt (5.2 percent in late 2010, according to IMF (2011a)) improves. On the other hand, global interest rates are low at present and might rise over the projection period, also raising the interest rate on Jamaica's public debt.

The choice of interest rate has implications for the estimated costs incurred by additional infections. At an interest rate of five percent, this is estimated at $\$ \$ 500,000$, or US\$5,800. At a lower interest rate of three percent, the estimated costs would be higher (as future spending is valued higher), at $\$ \$ 691,000$. At an interest rate of seven percent, the costs incurred by a new infection are equivalent to J $\$ 377,000$.

Public debt and interest

\begin{tabular}{lccc} 
& $\mathbf{2 0 0 8 / 0 9}$ & $\mathbf{2 0 0 9 / 1 0}$ & $\mathbf{2 0 1 0 / 1 1}$ \\
\hline Public debt (percent of GDP) & 108.9 & 119.1 & 118.6 \\
Denominated in J\$ & 45.9 & 51.5 & 50.1 \\
Denominated in foreign currency & 63.0 & 67.6 & 68.5 \\
Nominal interest rate on public debt & & \\
Domestic & 18.3 & 26.7 & 15.2 \\
Foreign & 6.1 & 6.0 & 5.0 \\
Inflation (consumer price index) & & & 11.4 \\
Jamaica & 12.4 & 9.7 & 2.7 \\
Foreign (United States) & -0.4 & 2.3 & 3.4 \\
Implied real interest rate & & & 2.3 \\
Domestic & 5.3 & 15.5 & 3.6
\end{tabular}

Data sources: Jamaican authorities, as reported by IMF (2011a).

The interest rate on public debt was calculated based on annual interest payments. U.S. inflation was obtained from U.S. Bureau of Labor Statistics (http://www.bls.gov/cpi/).

situations in which an HIV infection is delayed rather than prevented forever. A delay in an HIV infection means that the expected costs of providing HIVIAIDS services occur later and the amount that would need to be put aside now to meet these future costs declines (as the money put aside could earn some interest for longer). For example, a delay in an HIV infection by one year results in a financial saving equivalent to $\$ 25,000$, or about US\$290. ${ }^{17}$

To illustrate how these methods can be used in practice, consider the cost-effectiveness of Jamaica's program for the prevention of mother-to-child transmission (PMTCT) of HIV. As disease progression and unit costs of treatment differ from adults, the cost savings of one HIV infection prevented at or around birth is also different-estimated at J $\$ 483,000$ (equivalent to US\$5,600). The total costs of the program for the prevention of mother-to-child transmission of HIV (i.e., screening of pregnant women for HIV and providing treatment for the prevention of mother-to-child transmission to women requiring it) are estimated at around $\mathbf{J} 33$ million in 2012, which results in about fifty HIV infections averted in that year. Preventing these fifty HIV infections results in a financial saving equivalent to J\$24.2 million. The net costs of the PMTCT program in that year therefore equals I\$ 8.8 million, and the net costs per pediatric HIV infection averted is equal to $\$ 176,000$.

\footnotetext{
${ }^{17}$ As the expected costs are also delayed by one year, all costs are additionally discounted by one year's interest. The financial savings from a one-year delay are therefore calculated as one year's interest rate (here: five percent) times the costs incurred by one infection $(J \$ 500,000)$, which is equal to J $\$ 25,000$.
} 


\section{Prevention Policies and the Drivers of HIV Incidence}

The analysis so far has focused on the consequences of an HIV infection in terms of the costs of providing HIV/AIDS-related services for the individual infected. However, to assess the cost-effectiveness of HIVIAIDS policies, it is necessary to understand the implications of an intervention on the population level. This distinction is important-an individual contracting HIV may infect further people, augmenting the consequences of the initial HIV infection. This point is particularly relevant in Jamaica, which is facing a concentrated HIV epidemic, and where certain population groups play a disproportionate role in the spread of the epidemic.

The ongoing "modes-of-transmission" (MOT) study ${ }^{18}$ offers an opportunity to analyze the consequences of additional HIV infections across population groups, including the risk that an infected individual passes on the virus. The MOT study differentiates between female sex workers, their male clients and the female partners of their clients; men who have sex with men and their female partners; individuals engaging in casual heterosexual sex and their partners, low-risk heterosexual individuals and no-risk individuals who are not sexually active. HIV incidence, and the probability that an individual passes on the virus, differ vastly across these groups. For example:

- HIV incidence among (non-infected) men who have sex with men is estimated at 2.7 percent. HIV-positive men who have sex with men, over the course of their infection, infect 1.8 additional men who have sex with men and 0.4 of their female partners. Coverage of preventive behavior is estimated at 50 percent.

- HIV incidence among female sex workers, where condom coverage is believed to be high (about 90 percent) is estimated at 0.3 percent. According to the MOT study, each female sex worker may infect 2.2 clients, and each client would pass on the virus to 0.6 of their female partners and to 0.2 sex workers.

- Individuals engaging in casual heterosexual sex are expected to infect 0.5 others through sexual activity. Additionally, male individuals infect 0.4 female partners from the low-risk population.

- Low-risk individuals face a low-risk of contracting HIV (0.1 percent), but if infected are likely to pass the virus on to their partners, as condom use in this population group is low. HIV incidence in the low-risk population is about the same as among the population engaging in casual sex, owing to lower rates of condom use (17 percent, compared to 65 percent in the casual-sex population).

Table 3 summarizes the estimated costs incurred by new infections, including allowances for the costs resulting from "downstream" infections. The latter are calculated based on the expected number of people to whom an individual newly infected passed the virus on to, and so on, and the expected costs of providing HIVIAIDS-related services to the people infected, applying (as elsewhere in this study) a discount rate of 5 percent. For the low-risk and casual-sex pop-

\section{Table 3. Costs Incurred by HIV Infections, by Population Group}

\begin{tabular}{lrr} 
& (in J\$) & (in US\$) \\
\hline $\begin{array}{l}\text { Direct costs incurred by HIV infection } \\
\text { Additional costs from "downstream" }\end{array}$ & 500,000 & 5,800 \\
infections & & \\
$\quad$ Low-risk individual (male or female) & 361,000 & 4,200 \\
Casual sex (male) & 407,000 & 4,700 \\
Casual sex (female) & 303,000 & 3,500 \\
Female sex worker & $2,115,000$ & 24,600 \\
Men who have sex with men & $4,832,000$ & 56,300
\end{tabular}

Source: Author's calculation.

ulations, the increased risk of further HIV infections adds between I\$ 303,000 and $J \$ 407,000$, or an additional 60 percent to 80 percent, to the costs directly incurred by a new HIV infection. For these groups, the total financial savings from one HIV infection prevented are therefore between $\mathbf{J} \$ 803,000$ to $\mathbf{J} 907,000$. This is the value that should be applied in assessing the cost-effectiveness of HIV interventions targeting the general population.

For female sex workers, the cost of downstream infections are estimated at around $\$$ \$ 2.1 million (US\$24,600), four-fold the direct costs. This reflects the risk that a female sex worker infects her clients, who may pass on the virus to more female sex workers (and so on) and to their regular partners. These high costs already reflect an estimated coverage rate of condom use of 90 percent; without it, the costs of onward infections would be higher.

Estimating the costs on "downstream" infections for men who have sex with men is challenging because the draft MOT study estimates that HIV incidence in this group is on an explosive path (with each new infection resulting in 1.8 infections in the next round, and so on). This rate would come down as the HIV prevalence among men who have sex with men rises and fewer remain to be infected. Eventually, HIV prevalence among men who have sex with men stabilizes at a level where each man who has sex with men infects about one other. To estimate the expected costs of downstream infections, it is assumed that each infection among men who have sex with men now directly results in 1.8 "downstream" infections but that this rate will come down to one in later rounds (as HIV prevalence has risen in between). On this basis, the costs from "downstream" infections among men who have sex with men add up to $\mathrm{J} \$ 4.8$ million (US\$ 56,300 ) almost ten-fold the direct costs.

${ }_{18}$ The MOT study calculates the expected number of new infections per year on the basis of the current distribution of infections and patterns of risk within a population. It uses data from different studies to generate an estimate of the specific populations contributing to HIV incidence. 


\section{Fiscal Evaluation of the Costs of the HIV/AIDS Program}

The discussion so far has focused on two different perspectives on the fiscal burden of the national response to HIVIAIDS, namely: (1) the projected costs of the national response to HIVIAIDS over the period 2010 to 2030 and (2) the link between HIV incidence and the subsequent costs of providing HIV/AIDS services. The current section merges these approaches, attributing the costs of the national response to HIVIAIDS explicitly to HIV infections.

Even though most of the demand for HIVIAIDS-related services is ultimately caused by HIV infections, the long lags between infections and need for treatment or other services means that the costs of the national response to HIVIAIDS are barely responsive to changes in HIV incidence in the short-term. In the three scenarios discussed earlier, a large change in HIV incidence (43 percent by 2030) resulted in a reduction of spending of only 11 percent in 2030.

An alternative view of the fiscal costs of the response to HIVIAIDS is developed in this section that attributes most HIVIAIDS spending directly to the underlying HIV infections. This helps to resolve the apparent inconsistency that most HIVIAIDS spending is caused by HIV infections, but that HIVIAIDS spending barely budges as the number of HIV infections changes, and to gain a better understanding of the fiscal consequences of alternative HIVIAIDS policies.

This analysis is based on the discussion in the previous section on the costs incurred by each individual infection, which provided estimates of the actuarially fair costs incurred by one additional infection. If each infection in 2012 incurs a cost of $\$ \$ 500,000$ and there are 2,000 new HIV infections, then the total fiscal costs incurred by new infections in 2012 is $\$$ 1,000 million. This is the amount the government would have to set aside in 2012 to cover the anticipated costs of providing HIV/AIDS services to all people who got infected in 2012.

Thus, the policy commitments of the National HIVIAIDS Program are interpreted as spending commitments. For Scenario 1, the costs incurred by new infections in 2012 are estimated at J\$970 million (1,940 infections at J\$500,000 each). Additionally, it is necessary to take into account the spending that does not directly meet the needs of people living with HIVIAIDS and cannot therefore be attributed to the underlying 
HIV infections. This population-based spending-largely prevention spending targeting the general population or sub-populations, but not necessarily people living with HIV, as well as certain administrative expenses-is estimated at J\$805 million (US\$ 9.5 million) in 2012. The total costs of the National HIVIAIDS Program on a commitment basis therefore adds up to $\$$ 1,775 million (US\$20.9 million) under Scenario 1. Looking ahead, the total financial commitments under the HIV/AIDS program can be calculated similarly. The costs over time of serving all people living with HIVIAIDS who are currently alive add up to 3.4 percent of GDP. ${ }^{19}$ This number has been calculated in the same way that the costs incurred by a new infection were calculated, as the actuarially fair value that the government would have to set aside now to cover the future costs of HIVIAIDS services to people currently living with HIVIAIDS, plus population-based spending.

Similar to the earlier discussion on the cost-effectiveness of specific prevention interventions, the current analysis can be used to evaluate the cost-effectiveness of alternative HIVIAIDS programs. Figure 10 shows current HIVIAIDS spending and new spending commitments caused by HIV infections for Scenario 1 (declining HIV incidence) and Scenario 3 (increasing HIV incidence). Actual spending increases throughout the projection period (from 0.15 percent of GDP in 2010 to 0.20 percent of GDP in 2030 in Scenario 1, and 0.22 percent of GDP in Scenario 3). Coincidentally, the financial commitments caused by new HIV infections are initially about equal to current spending on people living with HIVIAIDS, at 0.08 percent of GDP. ${ }^{20}$

From this time on, however, the financial commitments caused by new infections diverge between Scenario 1 and Scenario 3. Between 2010 and 2015, they remain broadly constant in Scenario 1, reflecting two opposing forces-treatment coverage rates are assumed to increase in this period (so that the expected costs caused by each HIV infection increase), while HIV incidence declines. In contrast, the costs incurred by new HIV infections increase in Scenario 3, and by 2015 the additional costs implied by the higher number of HIV infections (relative to Scenario 1) amount to J\$ 205 million (US\$ 2.4 million)in this scenario. The costs of the HIVIAIDS program, taking into account the spending commitments implied by new HIV infections, is thus 11 percent higher by 2015, compared to Scenario 1 in which HIV incidence declines.
After 2015, treatment coverage rates are assumed to be constant (and the same across scenarios), so that the changes in the costs incurred by new infections more directly reflect the course of HIV incidence. In Scenario 1, spending commitments caused by new infections decline relative to GDP from 2015 to 2030, broadly in line with declining HIV incidence (the other factors at play are GDP growth and changes in unit costs of HIVIAIDS services, some of which include human resource costs and are linked to GDP per capita). In this scenario, the costs incurred by new HIV infections reach 0.05 percent of GDP by 2030 , and the total costs of the HIV program (on a commitment basis) decline to 0.12 percent of GDP over this period.

In Scenario 3, by contrast, the costs incurred by new infections remain higher, at about 0.09 percent of GDP over the projection horizon, ${ }^{21}$ and consequently the total costs of the HIV program (on a commitment basis) remain at 0.17 percent of GDP. The cost savings from the decline in HIV incidence between Scenario 3 and Scenario 1 thus result in fiscal savings which rise to 0.04 percent of GDP (about one-quarter of the costs of the HIVIAIDS program) by 2030 .

Figure 11 illustrates the differences between the scenarios more directly. By 2015 , when actual spending barely budges, the costs in-

\footnotetext{
${ }^{19}$ For some purposes, it is useful to also include the estimated costs incurred by projected future infections, and not only HIV infections which have already occurred, in the estimate of fiscal space absorbed by the national response to HIVIAIDS. This wider estimate of the fiscal costs of HIVIAIDS adds up to 4.8 percent, of which 1.4 percent of GDP represent the expected costs of projected infections.

20 This reflects two factors: (1) Without changes in underlying factors (HIV incidence, coverage rates) the costs incurred by new infections would be lower than current spending, because the former involve discounting. (2) Because of the ongoing scaling-up of treatment, people newly infected have a better chance of obtaining treatment, while cohorts who acquired HIV earlier have been depleted because of a relative lack of treatment (reducing current spending).

${ }^{21}$ While the costs incurred by new infections increase in absolute terms in Scenario 3, in line with the increasing HIV incidence, GDP also grows over the projection period, and the costs remain broadly constant relative to GDP.
}

Figure 10. Fiscal Costs of HIV/AIDS, Commitment Basis,2010-2030

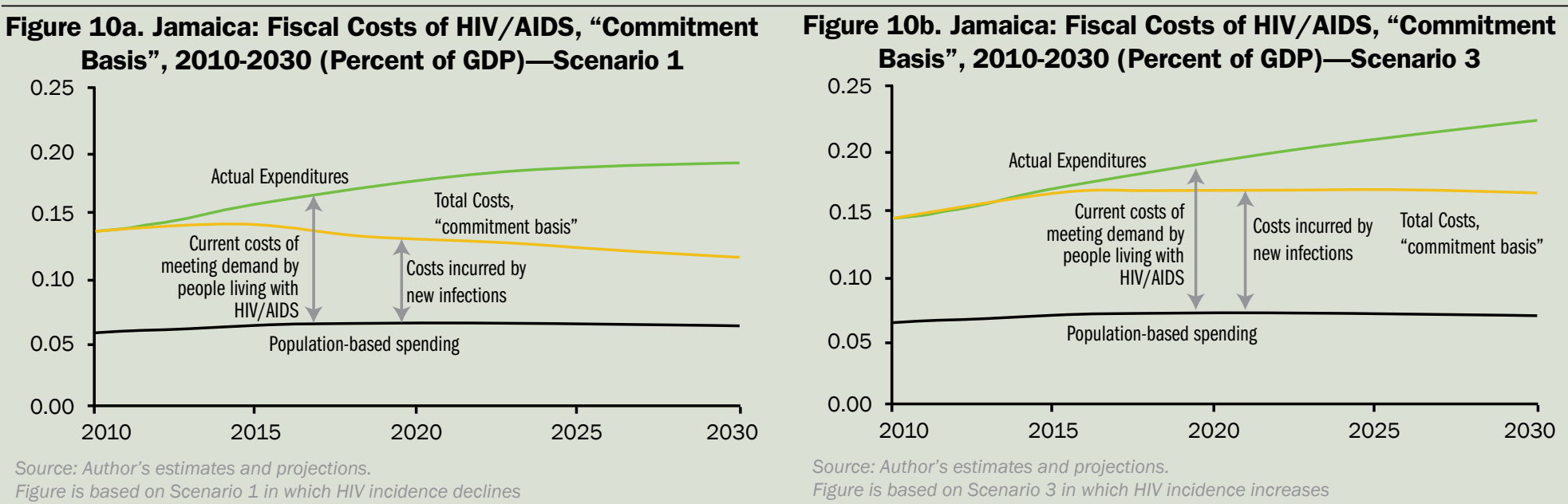


Figure 11. Fiscal Costs of HIV/AIDS, Current and

Commitments, Across Scenarios (Percent of GDP)

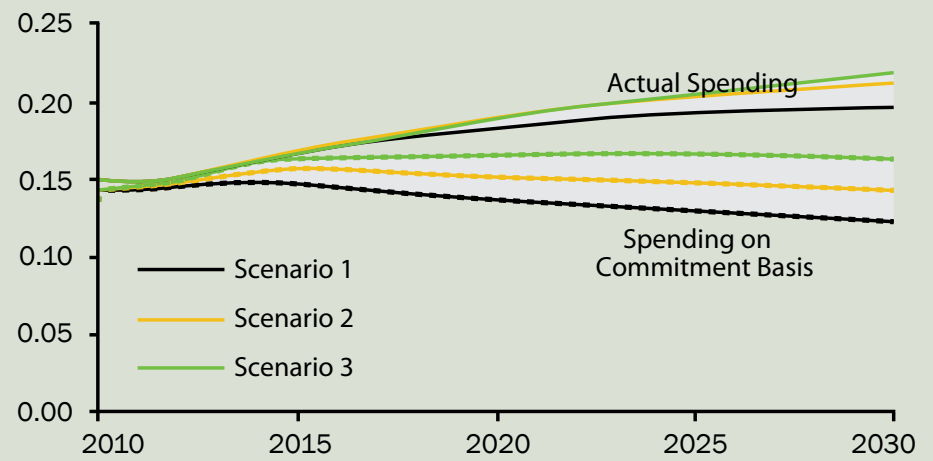

Source: Author's estimates.

curred by new infections in the scenario with reduced HIV incidence are already reduced by over $\$ \$ 100$ million (0.01 percent of GDP) compared to the scenario with constant HIV incidence, and by over I\$ 200 million compared to the scenario envisaging an increase in HIV incidence (at constant 2010 prices). This gap increases to J\$ 196 million by 2020 and J\$294 million by 2030 (relative to the scenario with constant HIV incidence), or to J\$ 379 million by 2020 and $J \$ 623$ million by 2030 (relative to the scenario envisaging an increase in HIV incidence).

These findings are relevant for the design and evaluation of HIVIAIDS policies in various ways:

- $\quad$ The analysis provides accurate estimates of the financial implications of alternative HIVIAIDS policies, including the implications of changes in HIV incidence for spending needs.
- Similar to the analysis of the costs incurred as a consequence of individual HIV infections, which provides the basis for an analysis of the cost-effectiveness of specific HIV interventions, the program-level analysis provides a tool (together with the resulting health outcomes) to rank alternative policies in terms of their cost-effectiveness.

- The present analysis merely highlights the consequences of higher or lower effectiveness of HIV prevention interventions but does not specify where this derives from. Together with a more specific policy framework, and more explicit epidemiological modeling, the analysis supports the design of cost-effective HIVIAIDS policies, linking the costs of alternative HIV prevention interventions, their outcomes for the course of the epidemic, and the consequences in terms of the costs of the resulting demand for HIVIAIDS services. 


\section{Sustainability of the National Response to HIV/AIDS}

The financial sustainability of the national response to HIVIAIDS in Jamaica faces challenges that arise primarily from two sources:

- The projected increase in the costs of providing HIV/AIDS services, largely because the number of people eligible for and receiving treatment expands greatly over the coming years.

- The outlook for Jamaica in obtaining external funding is uncertain. As availability of external funding is expected to decrease, the need for domestic financing to sustain the HIV/AIDS program and meet the increased demand for services will increase.

These challenges occur against a background of tight public finances, so that claims for additional government funding will be closely scrutinized. The analysis thus far makes a contribution to dealing with these challenges (1) by focusing on quantifying the financing challenges, offering projections of the costs of the national response to HIVIAIDS until 2030, and (2) by describing some tools for assessing the cost-effectiveness and allocative effectiveness of HIVIAIDS interventions and HIVIAIDS programs. The current section pulls together some of the lessons regarding the current and impending policy challenges, looking at:

- The implications of reduced availability of external financing.

- The cost-effectiveness of HIV/AIDS interventions.

- The allocative effectiveness of HIVIAIDS interventions, especially of investments in HIV prevention.

- Financing of expanding treatment needs.

\section{Implications of Reduced Availability of External Financing}

External support has played a large role in the financing of Jamaica's national response to HIV/AIDS. According to the latest available data (Figure 12, also recall the discussion in Section 2), external financing accounted for around two-thirds (68.8 percent) of the costs of the national response to HIV/AIDS. By far the most substantial financial contribution was from the Global Fund (48.8 percent of total spending, 


\section{Figure 12. Composition of Financing of National Response to HIV/AIDS, 2010 (Percent of Total Public HIV/AIDS Spending)}

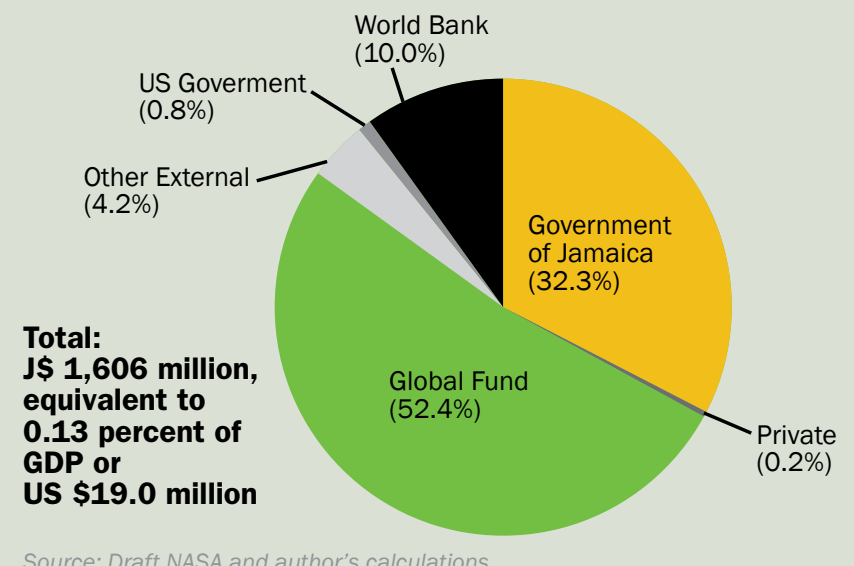

and 71 percent of external support), followed by the World Bank (9.3 percent of total spending) and the United States Government (1.4 percent of total spending). ${ }^{22}$ The Government of Jamaica accounted for almost one-third of total spending (31.0 percent), while private domestic spending does not play a role in recorded HIVIAIDS spending. ${ }^{23}$

Most external funding is not secured beyond the near future. The World Bank project will close in November 2012, the Global Fund grant will end in 2013 and the bulk of the support from the United States Government will terminate in 2014. These uncertainties are compounded by a stagnating or negative global outlook for HIVIAIDS funding. Most significantly, the Global Fund has recently postponed its new call for proposals ("Round 11") —for which the Government of Jamaica had prepared a submission — and has introduced tighter eligibility criteria.

Compared to other countries, the extent of external support for Jamaica's HIVIAIDS program has been relatively strong. Figure 13 summarizes the available data on the external contributions to the financing of HIVIAIDS programs for 2009 (from UNAIDS 2010), based largely on data from NASAs and UNGASS reports. The extent of external support in Jamaica is among the highest compared to countries at a similar level of economic development, but it is well within the range enjoyed by countries with a similar level of HIV prevalence. However, those countries with a similar level of HIV prevalence but which enjoy a higher rate of external support (Guinea, Djibouti, and Guinea-Bissau) are characterized by much lower level of GDP per capita.
The changing global funding environment will already have a significant impact on the financing of Jamaica's HIVIAIDS program over the next few years. Contributions from the Global Fund will be much reduced according to the new funding criteria introduced in 2011; it is also by no means certain that Jamaica will obtain any new funding from the Global Fund at all. These criteria mean that Global Fund support cannot exceed two-thirds of the budgetary resources committed by the Government of Jamaica. ${ }^{24}$

To illustrate the implications in this change in funding criteria, the new criteria are applied retroactively to HIVIAIDS spending and fund-

${ }^{22}$ The NASA did not clearly identify collateral financing by the Government of Jamaica of projects supported by the World Bank (I\$ 40 million) and the United States Government (J\$ 15 million). In Figure 11, the amounts spent by the Government of Jamaica are netted out from spending supported by the World Bank and the United States Government.

${ }^{23}$ This is also a consequence of data limitations, as there are no estimates available of the private costs of accessing HIVIAIDS services. Data from household surveys (compare Section 2) suggest that wealthier quintiles predominantly use private health services, but it is possible that this is not the case for specialized HIV/AIDS services.

${ }^{24}$ For upper-middle-income countries (according to World Bank definition) like Jamaica, the Global Fund demands that proposals meet a "minimum threshold for counterpart financing" of 60 percent, i.e. total HIVIAIDS funding from the domestic budget needs to account for at least 60 percent of the sum of total domestic budgetary funding and Global Fund support.

\section{Figure 13. Role of External HIV/AIDS Financing, 2009 (Percent of total spending)}

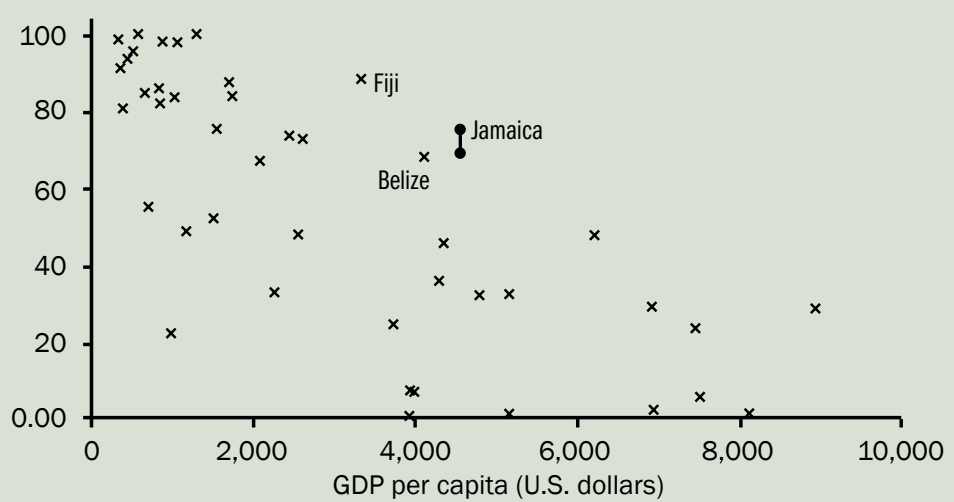

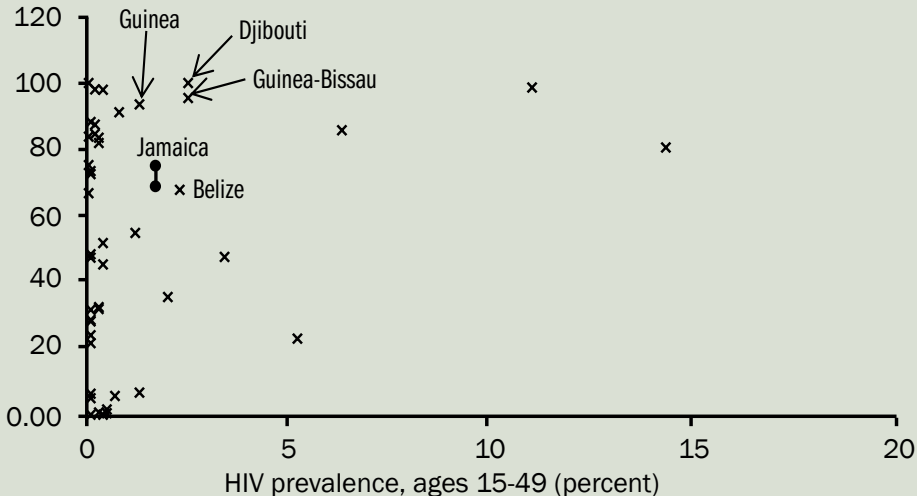




\section{Figure 14. Domestic Financing Need and Rate of External Support (J\$ millions, 2010 prices)}

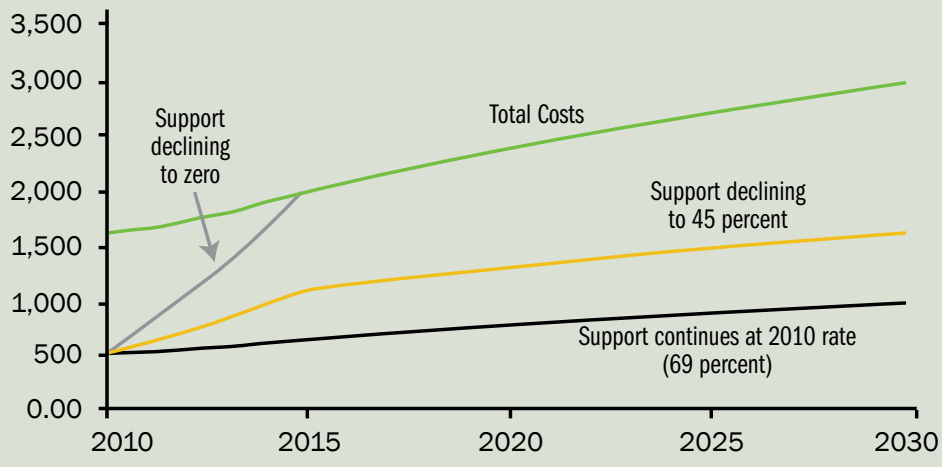

Source: Author's estimates and projections.

ing in 2010, when 31.0 percent of the total costs of the national response to HIV/AIDS were funded by the Government of Jamaica, ${ }^{25}$ and 48.8 percent of the total costs were contributed by the Global Fund. Under the new funding rule, the share of the national government would need to rise to 47.8 percent (i.e., from $\mathbf{~} \$ 535$ million to J\$ 826 million).

The estimates of total spending used in the current study, however, include expenditures addressing the impact of HIVIAIDS which are not formally included in the national response to HIVIAIDS, notably a share of the CDA budget (J\$275 million in 2010). If this is not accepted as counterpart financing by the Global Fund, then domestic financing would need to rise to $\$ \$ 937$ million (54.2 percent of the total costs).

For the longer-run projections, assumptions regarding the availability of external funding are largely speculative at this stage. To illustrate the consequences of shifts in external funding, Figure 14 illustrates various possibilities (based on Scenario 1, with declining HIV incidence). With rising spending needs, a decline in the rate of external support will result in an even steeper increase in domestic funding needs. For example, if the rate of external support declines from 69 percent to 45 percent (broadly in line with the changed Global Fund criteria), domestic funding needs will need to double by 2015 , from J $\$ 539$ million (US\$ 6.3 million) in 2010 to J\$ 1, 144 million (US\$ 13.5 million) in 2015, and increase to J\$1,353 million (US\$15.9 million) by 2020, and J\$1,683 million (US\$ 19.8 milllion) by 2030 .

Across scenarios, the consequences of the decline in external funding are fairly even initially, because the assumed changes in HIV incidence affect spending with a long lag. For example, if external support drops to 45 percent of the costs of the national response to HIV/ AIDS, domestic funding needs in 2015 differ by about I\$ 4 million (US\$ 46,000) by 2015 between Scenario 1 (declining HIV incidence) and Scenario 3 (increasing HIV incidence). However, as the assumed changes in HIV incidence feed through to HIVIAIDS spending, the difference in domestic funding needs between Scenario 1 and Scenario 3 rises to $\$ 33$ million(US\$390,000) by 2020, and J\$ 183 million(US\$2.2 million) by 2030 .

Thus, successful HIV prevention interventions-under a wide range of assumptions regarding the extent of forthcoming external supportwill have an increasing and potentially large impact on the domestic financing needs of the National HIV/AIDS Program. While these are slow to materialize (owing to long lags between HIV infection and treatment), they play an important role for sustaining the funding of the HIVIAIDS program in the longer run.

One aspect of attaining the financial sustainability of the National HIV/ AIDS Program is to ensure that HIV/AIDS interventions are delivered in a cost-effective manner and-where there is a choice between different measures-that the most cost-effective interventions are chosen and that the available funds are allocated in the most efficient manner.

The focus of the present study is on the fiscal costs of the HIVIAIDS program overall, rather than the analysis of specific HIVIAIDS interventions and the design of the HIVIAIDS program. Nevertheless, the tools applied here-explicitly linking the costs of the HIVIAIDS program to the underlying HIV infections - are suitable to address such issues as allocative efficiency in the HIVIAIDS program.

Specifically, the estimates of the costs incurred by one HIV infection, under the objectives of the National HIVIAIDS Program, provide a yardstick for assessing the cost-effectiveness of HIV/AIDS interventions. Cost-effectiveness is then calculated relating the health outcomes of interest (HIV infections averted, life years saved, etc.) to the costs of the intervention, minus the financial savings implied by the reduced number of HIV infections.

In addition to the challenge of assessing and attaining cost-effectiveness, effective spending allocation involves comparisons and choices between different types of interventions-for example, between prevention interventions that target different population groups. The contribution of this study to assessing the allocative efficiency of HIVIAIDS interventions is a framework that allows for comparisons to be made between the outcomes and financial consequences of the different interventions. To this end, it is necessary to (1) assess the impacts of an intervention at the population-level in addition to

\footnotetext{
${ }^{25}$ Additionally, the loan from the World Bank may be counted as domestic financing as it will need to be repaid by the Government of Jamaica, unlike the grant financing from the Global Fund. If spending supported by the World Bank loan can be counted as domestic funding, the share covered by the national government would need to rise to 44.1 percent (in addition to the World Bank loan), or 50.5 percent if a part of the CDA budget is not accepted as counterpart financing.
} 
its direct impacts (infections prevented in targeted group, and resulting health gains and financial savings), and (2) consider the consequences of such impacts at the population-level ("downstream" HIV infections averted, and the health gains and financial consequences resulting from these).

Many such decisions require a more explicit epidemiological analysis than the one offered here. Nevertheless, the analysis offers some lessons and examples for assessing the efficiency of spending allocations, namely:

- $\quad$ For the prevention of mother-to-child transmission of HIV the analysis estimates that the cost of averting one pediatric infection was $\mathbf{\$} 658,000$. Each pediatric HIV infection averted, however, results in expected savings of $J \$ 483,000$, so that the net costs of averting one pediatric HIV infection are $\mathbf{\$} \$ 176,000$.
- As to the consequences of HIV infections across population groups, the expected costs of providing HIVIAIDS services to one person living with HIVIAIDS from the time of infection are estimated at $\$ \$ 500,000$ (US\$5,800). However, the HIV epidemic in Jamaica is concentrated, so the probability that an HIV-positive person passes HIV on to another person (and so on) differs widely across population groups. Taking into account these downstream infections, the financial savings achieved by preventing one HIV infection is assessed at around J $\$ 800,000$ to $\mathbf{} \$ 900,000$ for the general population ("low risk" or "casual sex"), J\$2.6 million for female sex workers and $\mathbf{\$} \$ 5.3$ million for men who have sex with men. To assess the allocative efficiency of HIVIAIDS spending across prevention interventions, it is necessary to take into account the population-level impacts of the intervention (including downstream infections prevented and the resulting health outcomes), as well as the resulting financial savings.

\section{Funding Treatment Costs}

The financing of treatment costs is one of the greatest financial challenges in sustaining the HIVIAIDS program over the coming years. Treatment costs are expected to rise sharply because an increasing number of people living with HIVIAIDS will receive treatment and the increasing need for second-line treatment will drive up average costs. In addition, the (drug) costs of antiretroviral treatment are currently supported by the grant from the Global Fund, and the outlook for funding from this source after expiry of the current arrangement in 2013 is uncertain.

Should external funding for the treatment program no longer be available (or be much reduced), the funding of the treatment program would not pose unusual challenges, from a public health perspective. HIV/AIDS-related health spending (approximated by the costs of care and treatment, the prevention of mother-to-child transmission, and counseling and testing) amounted to $\$ \$ 800$ million in 2010 , corresponding to two to three percent of public health spending. This amount seems in line with the contribution of HIVIAIDS to the burden of disease-the epidemic accounts for about eight percent of deaths, one-half of the deaths from communicable diseases among the overall population, and one-quarter of deaths among the population aged 15-59 years (WHO, 2011).

More specifically, the annual costs of antiretroviral treatment (drugs, tests and human resources), based on current estimates provided by the Clinton Health Access Initiative, are equal to nine percent of GDP per capita $(J \$ 41,000)$ and 21 percent of GDP per capita $(J \$ 88,000)$ for first- and second-line therapy, respectively. These costs may understate the cost of extending life by one year (as patients would survive without treatment for some period) but do not include financial savings in other areas, e.g., reduced non-antiretroviral treatment costs, savings in social mitigation expenses and a reduced risk of onward HIV transmission ("treatment as prevention").

Setting aside these uncertainties, the costs of treatment nevertheless appear far below benchmarks commonly used in assessing the cost-effectiveness of health interventions. For example, the WHO would consider health interventions that save a life year at a cost that is lower than GDP per capita as "highly cost-effective" and the economic literature adopts values well exceeding GDP per capita in the cost-benefit analysis of health or environmental interventions (see, e.g., Murphy and Topel, 2006). Compared to these benchmarks, the costs of antiretroviral treatment in Jamaica (about 10 percent of GDP per capita for first-line treatment, and 20 percent of GDP per capita for second-line treatment) are relatively small.

Beyond the immediate health outcomes, it is plausible that HIVIAIDS exacerbates social inequities in access to health. The Jamaica Survey of Living Conditions 2009 (STATIN and PIOJ, 2010) highlighted the fact that poorer households were less likely to seek medical services in an episode of illness and that the costs for those households seeking care were high relative to income. At a cost that is equivalent to over 60 percent of consumption per capita, even first-line treatment would be unaffordable for many members of the poorest consumption quintile (especially considering that it is a persistent health condition).

One policy proposal that is being considered is the funding of antiretroviral drugs through the National Health Fund (NHF), which purchases and markets essential drugs at subsidized prices and is financed by the National Insurance Fund, which provides coverage to all residents. Among the advantages of providing antiretroviral drugs through the NHF is the possibility to solicit (income-dependent) co-payments for the drugs, which could help contain the fiscal costs while addressing equity challenges. However, the costs of antiretroviral drugs are large relative to the budget of the NHF, which paid out benefits of about J\$ 1.5 billion in FY 2007/08 (NHF, 2009). The costs of antiretroviral drugs are estimated at about $\$ 230$ million in 2012 and are projected to rise to $\mathbf{J} 330$ million by 2015 , and to J\$ 540 million by 2020 in Scenario 1 (J\$ 560 million in Scenario 3). The NHF would therefore require additional funding to take on such increased responsibilities. 


\section{Conclusions}

The national response to HIV/AIDS faces considerable financing challenges, arising from the rising costs of the HIVIAIDS program (largely reflecting the increasing need for treatment), an uncertain and probably negative outlook for the availability of external funding and tight public finances. To inform the future policy response of the Government of Jamaica, this study set out to (1) review current spending on HIV/ AIDS and the sources of financing; (2) estimate the fiscal burden of the national HIVIAIDS response and assess the outlook for external financing of the HIV program; (3) project how the epidemic will unfold as well as what the costs would be under different scenarios; and (4) provide recommendations to inform policy decisions.

Key findings include:

- The costs of the national response to HIVIAIDS are estimated at about J\$1.7 billion (US\$20.4 million) as of 2010/11 (0.14 percent of GDP), of which about one-third is financed from the domestic budget and the rest from external sources.

- Spending needs will rise steeply over the coming years to about J $\$ 2.5$ billion (US\$28 million) by 2020, largely as a consequence of the increasing number of cases needing treatment and the increasing need for the use of second-line drug treatment. Current gains in HIV prevention will reduce spending needs only very slowly_owing to the long and variable lags between HIV infection and treatment need. Improved prevention outcomes are therefore no quick fix for the funding needs of the HIVIAIDS Program.

- The Government of Jamaica currently pays for about one-third of the costs of the national response to HIVIAIDS. Agreements with major funders (Global Fund, World Bank, U.S. Government) are set to expire over the next few years. The recent change in the Global Fund's funding criteria would mean that the share financed by the Government of Jamaica would need to rise to at least one-half.

- With total costs to the Government of Jamaica remaining around 0.2 percent of GDP over the coming years (minus any external support), the challenges for financing the national HIVIAIDS Program is manageable and fiscally sustainable provided HIVIAIDS remains a national development priority. 
- $\quad$ Treatment costs appear to be in line with the burden of disease and health spending in general. Overall HIVIAIDS spending is about three percent of public health spending, which appears consistent with the burden of disease. Also, the annual costs of treatment (about 10 percent of GDP per capita for first-line treatment and 20 percent of GDP per capita for second-line treatment) are within a range that could reasonably be supported through public health spending.

- Moreover, public provision of treatment fulfills a broader social role, as HIVIAIDS is a persistent health condition that is expensive to care for and treat, and that therefore is likely to exacerbate social inequities in accessing health.

- New infections eventually result in additional demands for services which are expensive and may extend over several decades. Overall, the fiscal cost incurred by one additional HIV infection, under the objectives of the National HIV/AIDS Program, is estimated at J\$500,000 (US\$ 5,800).

- When the risk of onward infections is taken into account, the costs incurred by new infections range from $\$ \$ 800,000$ to J $\$ 900,000$ for the general population to $\$ \$ 2.6$ billion(about US\$ 30,000) for female sex workers and J $\$ 5.3$ billion (about US\$60,000) for men who have sex with men.

To take the national response to HIVIAIDS further, the study points to three priority areas for the Government:

1. Develop a long-term sustainability plan with different financing options that defines the roles of different national agencies (as well as donor agencies). This would build on the cost estimates presented here, as well as upon the public expenditure review of government programs and the cost analysis of other main disease programs and health spending in Jamaica. The sustainability of the National HIV Program cannot be achieved in isolation from other public expenditure programs. The sustainability plan will need to review possible sources of financing from both the public and private sectors and also institutional sustainability. The Government is moving in the right direction by (1) exploring the possibility of financing HIVIAIDS drugs through the NHF, which is funded by taxation; and (2) strengthening the institutional sustainability of the National HIV Program by integrating it with the Family Planning Board to create a Sexual and Reproductive Health Authority for Jamaica.

2. Assess the allocative efficiency of the national response to HIVIAIDS, taking into account not-only the immediate health consequences but also the epidemiological and financial repercussions of alternative HIVIAIDS interventions. This report contributes to such an analysis of cost-effectiveness by estimating the costs incurred by new HIV infections over time (so that the resulting savings can be netted out from the costs of prevention interventions) and by discussing the role of "downstream" infections (allowing an assessment of the cost-effectiveness of prevention interventions across population groups).

3. The allocative efficiency analysis needs to further assess spending choices across prevention activities. Jamaica will need to make stronger effort in reaching the most at-risk populations, particularly men who have sex with men, to prevent HIV transmission. This report clearly indicates that the costs incurred by new infections from sex workers and men who have sex with men are very high and that effective prevention in the short-term will result in lower spending on treatment in the long-term. 


\section{References}

Duncan, Jacqueline, Sharlene Beckford Jarrett, and Kevin Harvey, 2010, "Using Estimation and Projection Package and Spectrum for Jamaica's National HIV Estimates and Targets," Sexually Transmitted Infections, Vol. 86, Suppl. 2, pp. ii43-ii47.

Figueroa, J. Peter, and others, 2008, "A Comprehensive Response to the HIVIAIDS Epidemic in Jamaica - A Review of the Past 20 Years," West Indian Medical Journal, Vol. 57, No. 6, pp. 562-76.

Government of Jamaica (GoJ), 2008, "HIV and AIDS in Jamaica: National Strategic Plan 2007-2012, FINAL DRAFT, March 2008," (Kingston: GoJ).

Guthrie, Teresa, Nhlanhla Ndlovu, Farzana Muhib, Robert Hecht, and Kelsey Case, 2010, "The Long-Run Costs and Financing of HIV/ AIDS in South Africa" (Washington DC: Results for Development Institute).

Hecht, Robert, and others, 2010, "Financing of HIVIAIDS Programme Scale-up in Low-Income and Middle-Income Countries, 200931," The Lancet, Vol. 376, pp. 1254-60.

Heller, Peter S., 2005, "Understanding Fiscal Space," IMF Policy Discussion Paper No. 05/4 (Washington DC: International Monetary Fund).

Hogan, Daniel R, Rob Baltussen, Chika Hayashi, Jeremy A. Lauer, and Joshua A. Salomon, 2005, "Cost Effectiveness Analysis of Strategies to Combat HIVIAIDS in Developing Countries," British Medical Journal, Vol. 331, pp. 1431-7.

Hope Enterprises, 2008, "Report of Findings from HIVIAIDS Knowledge Attitudes and Behavior Survey, Jamaica 2008" (Kingston: Hope Enterprises Ltd.). International Monetary Fund (IMF), 2011a, "Jamaica: Third Review Under the Stand-By Arrangement - Staff Report" (Washington DC: IMF).

- 2011b, World Economic Outlook Database, September 2011 Edition (Washington DC: IMF).

, 2010, "Jamaica: 2009 Article IV Consultation and Request for a Stand-By Arrangement - Staff Report" (Washington DC: IMF).

Joint United Nations Programme on HIVIAIDS (UNAIDS), 2010a, UNAIDS Report on the Global AIDS Epidemic 2010 (Geneva: UNAIDS).

, 2010b, "HIV Estimates with Uncertainty Bounds, 19902009," obtained online at http://www.unaids.org/en/dataanalysis/epidemiology/ (Geneva: UNAIDS).
_ 2010c, "Getting to Zero: 2011-2015 Strategy" (Geneva: UNAIDS).

Lule, Elizabeth, and Markus Haacker, 2011, Fiscal Dimension of HIV/ AIDS in Botswana, South Africa, Swaziland, and Uganda(Washington DC: World Bank).

Ministry of Finance, 2011, "Jamaica Memorandum on the Budget" (Kingston: Ministry of Finance)

Ministry of Health $(\mathrm{MoH})$ and Joint United Nations Programme on HIVIAIDS (UNAIDS), 2012, Jamaica - National AIDS Spending Assessment (Kingston: Ministry of Health).

Ministry of Health/National HIV/STI Programme (MoH/NHP), 2012, "Country Progress Report Jamaica, Submitted March 30, 2012" (Kingston: Ministry of Health).

— 2010a, "Country Progress Report to the Secretary General of the United Nations on the United Nations General Assembly Special Session - Reporting period: January 2008-December 2009" (Kingston: Ministry of Health).

_ 2010b, "Jamaica HIV Epidemic Update, January to December 2009" (Kingston: Ministry of Health).

Murphy, Kevin M., and Robert Topel, 2006, "The Value of Health and Longevity," Journal of Political Economy, Vol. 114, No. 5, pp. $871-904$.

Phillips, Peter, 2012, "A New and Binding Covenant for Stability, Equitable Growth and Prosperity," Budget Debate Presentation to Parliament, May 24 (Kingston: Ministry of Finance).

Schwartländer, Bernhard, and others, 2011a, "Towards an Improved Investment Approach for an Effective Response to HIVIAIDS," The Lancet, Vol. 377, pp. 377, pp. 2031-41.

Schwartländer, Bernhard, and others, $2011 \mathrm{~b}$, supplementary web appendix to Schwartländer (2011a).

Statistical Institute of Jamaica (STATIN) and Planning Institute of Jamaica (PIOJ), 2010, Jamaica Survey of Living Conditions 2009 (Kingston: STATIN and PIOJ).

United Nations Children's Fund (UNICEF), 2011, State of the World's Children 2011 (New York: UNICEF)

United Nations Population Division (UNPD), 2011, World Population Prospects: The 2010 Revision (New York: UNPD).

World Health Organization (WHO), 2011, Global Health Observatory Data Repository (found at: http://apps.who.int/ghodata/), accessed August 2011 (Geneva: WHO). 


\section{Appendix on Methodology}

The analysis offered in this report combines three building blocks: (1) an epidemiological model, (2) a costing framework for projecting the costs of the national response to HIV/AIDS, and (3) an economic framework to calibrate the costs incurred by new infections.

\section{Epidemiological Framework}

The epidemiological framework is modeled following the estimates produced by the Ministry of Health using the Spectrum model, updated from the analysis described by Duncan and others (2010). As some of the economic analysis offered here (e.g., analyzing the consequences of individual infections over time) exceed the capabilities of the Spectrum model, the estimates and projections provided by the Ministry of Health were transformed into a spreadsheet-based model, which is integrated in the economic framework, and which has been calibrated to replicate the estimates and projections provided by the Ministry of Health.

Figure A1

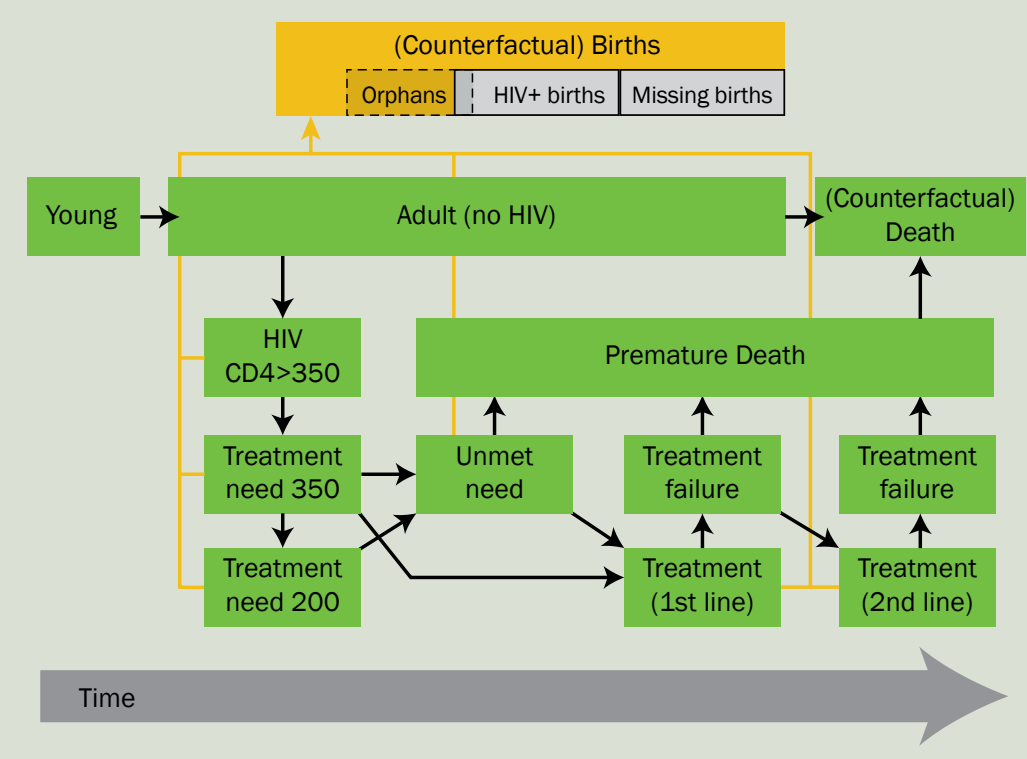


The structure of the epidemiological module is summarized in Figure A1. As an HIV infection occurs, adults move from state "no HIV" to "HIV+, CD4>350" (HIV positive, with a CD4 count above 350). Eventually, the CD4 count, in the absence of treatment, falls below 350 and 200, respectively. This distinction is important to replicate the estimates made by the Ministry of Health (which involve a switch in the treatment eligibility criterion from a CD4 count of 200 to a CD4 count of 350 in 2005-see main text, Figure 1b). However, in line with current government policy, projections are based on a CD4 eligibility criterion of 350 .

As individuals reach the stage "treatment need," they either initiate treatment, or progress to "unmet need" and eventually to premature death. Those receiving first-line treatment eventually reach first-line treatment failure and then progress either to initiate second-line treatment or to premature death. Individuals on second-line treatment eventually reach treatment failure and then premature death. Additionally, there is a module determining the impact of HIVIAIDS on the young population, including mother-to-child transmission of HIV and the impact of HIV on the number of orphans.

Specifically, the transitions between the states are governed by the following assumptions:

- $\quad$ The transition from HIV infection to eligibility for treatment at a CD4 count of 350 is based on a Weibull distribution, with a mean transition time of six years for males, and seven years for females. From this point, transition to eligibility for treatment at a CD4 count of 200 takes another three years (again based on a Weibull distribution). In the absence of treatment, death occurs on average three years after reaching a CD4 count of 200.

- The model can accommodate treatment initiation at a CD4 count of 350 or 200 (or a combination of the two possibilities). For individuals initiating first-line treatment at a CD4 count of 350 , transition to second-line treatment need takes 11 years, while for individuals who start at a CD4 count of 200, it is eight years. Unless second-line treatment is initiated, death occurs on average three years after reaching second-line treatment need.
- $\quad$ For individuals receiving second-line treatment, transition to treatment failure and death is determined by a Weibull distribution with a mean transition time of 10 years.

- Through 2015, the number of people initiating treatment is based on the estimates and projections provided by the Ministry of Health. Beyond 2015, 90 percent of people newly requiring treatment are expected to receive it, in line with the draft NSP.

- Through 2015, the transition to second-line therapy is based on estimates and projections received from the Ministry of Health. Thereafter, it is assumed that 90 percent of people receiving first-line treatment need move on to second-line treatment (consistent with the projections by the Ministry of Health).

- $\quad$ For new infections at age 0 (the model does not differentiate between infections before, at, or after birth), it is assumed that the probability of mother-to-child transmission is 24 percent (without interventions), that it is reduced by two-thirds through measures to prevent of mother-to-child transmission of HIV, and by two-thirds if the mother is receiving treatment.

- The number of orphans is estimated and projected based on a module that builds on male and female adult mortality, and on the survival probabilities of children (depending on treatment access).

One particular aspect of the epidemiology of HIVIAIDS in Jamaica is the high rate of outward migration, especially of people in the age groups where HIV incidence and prevalence are high. This means that many people infected with HIV in Jamaica leave the country before they require HIVIAIDS-related services. For example, 12 percent of men and 14 percent of women who become infected in Jamaica emigrate before reaching first-line treatment need (at a CD4 count of 350). These outflows have been taken into account, e.g., by specifying an annual migration rate at different stages of the disease (e.g., 2.4 percent for people above a CD4 count of 350).

\section{Projected Costs of National Response to HIV/AIDS}

The costs of the national response to HIVIAIDS are projected based on a straightforward costing model. The numbers of people receiving various types of HIVIAIDS-related services are based on the epidemiological estimates and the relevant coverage rates (based on the estimates and projections by the Ministry of Health or on the draft National Strategic Plan 2013-18. To this, unit costs are applied, based on estimated HIVIAIDS spending (as documented in the NASA report), budget data (e.g., for the costs of support to orphans) or direct estimates of unit costs (e.g., for treatment costs). These assumptions are documented in the main text (section "Assumptions on Unit Costs and Coverage Rates," page 20).

\section{Costs Incurred by New Infections}

One peculiar aspect of HIVIAIDS, greatly complicating the assessment of the financial implications of different interventions of program alternatives, is the fact that the costs of services required by a person living with HIVIAIDS are spread over a very long period of time, and could span several decades if an individual obtains access to treatment (which most do in the projections offered here, at a coverage 
rate of 90 percent). Current spending alone-without taking into account the state and course of the epidemic - is thus a very poor indicator of the fiscal burden of HIVIAIDS.

To provide a more accurate analysis of the fiscal burden of HIVIAIDS, the report therefore offers estimates of the actuarially fair value of the costs incurred by new HIV infections. For one new infection, this is the amount that the government would have to put aside at the time the infection occurs, in line with its policy commitments under the HIV/ AIDS program, in order to cover the expected life-time costs of providing HIVIAIDS-related services to the person who becomes infected. As the amount put aside would earn some interest until it is used to pay for HIVIAIDS-related services, future costs are discounted at an interest rate, which is based on the rate the government pays on its public debt (see Box 4- "Estimating the Financial Costs of New Infections"). The projections of the costs caused over time by one additional HIV infection, and estimates of the actuarially fair value of these costs, are documented in the main text (Figure 9, and pages 25-26).

However, not all HIVIAIDS spending can be attributed to earlier HIV infections in this way. This applies, in particular, to prevention spending that is directed at the general population or population sub-groups, irrespective of their HIV status. To distinguish it from spending to address the demands for services by people living with HIVIAIDS, this is referred to as "population-based" spending.

For a short-run analysis, e.g., projecting the financing needs of a national HIVIAIDS program over a few years, these different types of spending are similar. For an analysis of the financial consequences of alternative HIV policy options, however, these spending categories are very different in terms of the links between past HIV infections, current spending, and future resource needs.

The current demand for HIVIAIDS-related services and-under the government's policy commitments to provide certain HIVIAIDS-related services - the costs of meeting this demand are basically "locked in" by the number of infections which have occurred over the last years or decades. Spending in these categories is therefore barely responsive to any progress in reducing HIV incidence. To assess the fiscal consequences of alternative HIVIAIDS policies, the savings from reduced HIV incidence associated with an HIVIAIDS program are therefore estimated instead by the number of new HIV infections,

Table A1. Costs of Jamaica's National Response to HIV/AIDS

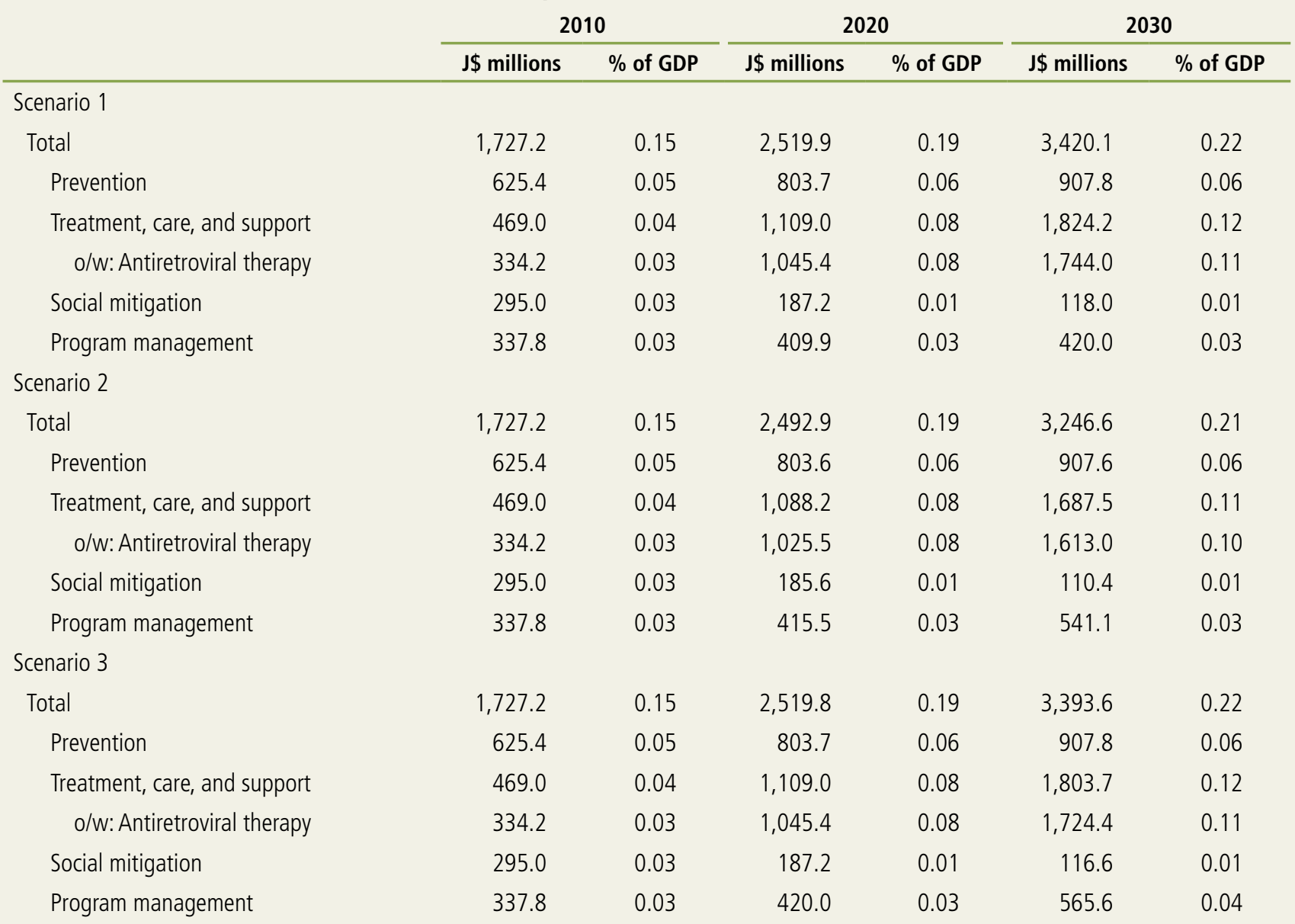


multiplied by the expected costs incurred by one infection. This method is illustrated on pages 29-31 which provides an interpretation of Jamaica's HIVIAIDS program in terms of fiscal space.

By contrast, as population-based spending cannot be attributed to previous HIV infections, and as current HIV infections do not cause future population-based spending, this spending category is treated as current spending in the analysis of the evolving fiscal burden of HIV/
AIDS. The two different types of spending are linked, however. As prevention spending (most of which would fall under the category of prevention-based spending) reduces the number of HIV infections (and the associated spending commitments), the analysis of the costs incurred by new infections is immediately relevant for the assessment of the cost-effectiveness of prevention interventions. This point is illustrated in the main text on page 27 in a discussion on the costs and resulting fiscal savings of the program to prevent mother-to-child transmission.

\section{Assessing Consequences of New HIV Infections across Population Groups}

The estimates of the costs incurred by one new HIV infection, together with estimates of the modes of transmission of HIVIAIDS, can be used to estimate the financial consequences of HIV infections across population groups, including the costs of "downstream" infections. The "modes of transmission" framework is first applied to estimate the expected number of downstream infections caused by one new HIV infection. For example, a female sex worker may infect two clients, and each client in turn infects 0.3 sex workers and 0.7 regular partners. This would mean that a new HIV infection among female sex workers over time results in an additional 1.5 infections among female sex workers later on-0.6 (=2 clients infected per sex worker, each expected to infect 0.3 additional sex workers) in the first round, 0.36 in the second, etc. Together with the initial infection, then, an expected total of 2.5 female sex workers become infected, which implies that a total of five clients (2.5 infections among female sex workers over time, times two clients infected per sex worker), and 3.5 partners of clients become infected (five clients, multiplied by 0.7 partners becoming infected per client). 

www.worldbank.org/lacaids

www.worldbank.org/aids 